NBER WORKING PAPER SERIES

\title{
HOW DO ELECTORAL RULES SHAPE PARTY STRUCTURES, GOVERNMENT COALITIONS, AND ECONOMIC POLICIES?
}

\author{
Torsten Persson \\ Gérard Roland \\ Guido Tabellini \\ Working Paper 10176 \\ http://www.nber.org/papers/w10176 \\ NATIONAL BUREAU OF ECONOMIC RESEARCH \\ 1050 Massachusetts Avenue \\ Cambridge, MA 02138 \\ December 2003
}

This research is supported by the Swedish Research Council, Bocconi University and the Communauté Française de Belgique, as well as a grant from the Center for Business and Policy Studies financing data collection. We are grateful to Antonio Merlo, Matthias Messner, Roger Myerson, Fausto Panunzi, Ken Shepsle and Dan Trefler, and seminar particpants at Bocconi, CIAR, IIES, MIT, Pennsylvania, LSE and Yale for helpful comments, and to Krister Lundell, Andrea Mascotto and Jose Mauricio Prado Jr. for skillful assistance with data. The views expressed herein are those of the authors and not necessarily those of the National Bureau of Economic Research.

C2003 by Torsten Persson, Gérard Roland, and Guido Tabellini. All rights reserved. Short sections of text, not to exceed two paragraphs, may be quoted without explicit permission provided that full credit, including (C) notice, is given to the source. 
How Do Electoral Rules Shape Party Structures, Government Coalitions, and Economic Policies? Torsten Persson Gérard Roland, and Guido Tabellini

NBER Working Paper No. 10175

December 2003

JEL No. H00, D72, D78

\section{$\underline{\text { ABSTRACT }}$}

We present a theoretical model of a parliamentary democracy, where party structures, government coalitions and fiscal policies are endogenously determined. The model predicts that, relative to proportional elections, majoritarian elections reduce government spending because they reduce party fragmentation and, therefore, the incidence of coalition governments. Party fragmentation can persist under majoritarian rule if party supporters are unevenly distributed across electoral districts. Economic and political data, from up to 50 post-war parliamentary democracies, strongly support our joint predictions from the electoral rule, to the party system, to the type of government, and to government spending.

Torsten Persson

Institute for International Economic Studies

Stockholm University

10691 Stockholm, Sweden

and NBER

torsten.persson@iies.su.se

Gérard Roland

University of California, Berkeley

549 Evans Hall, \#3880

Berkeley, CA 94720-3880

groland@econ.berkeley.edu

Guido Tabellini

IGIER Bocconi University

Via Salasco 5

20136 Milano, Italy

guido.tabellini@uni-bocconi.it 


\section{Introduction}

Recent empirical research by economists has demonstrated that electoral rules exert a strong influence on fiscal policy: majoritarian elections are associated with smaller government spending, smaller budget deficits and smaller welfare states, compared to proportional elections. Details of electoral rules seem to matter for corruption and effectiveness in government service provision, better performance being associated with larger electoral districts, and with individual rather than party-list ballots. ${ }^{1}$

For many years, political scientists have stressed the strong influence of electoral rules on the party structure: majoritarian elections are more likely to lead to a two-party system, while proportional elections often produce fragmentation of political parties. Moreover, these implications for party structure naturally spill over to the formation of governments: single-party majority governments are more common when parties are few, and coalition (or single-party minority) governments are the norm when parties are many. ${ }^{2}$

It is a plausible conjecture that these correlations in the data reflect a common causal chain. Proportional elections raise the number of parties in the legislature. This raises the incidence of coalition governments, and thereby increases the likelihood of higher government spending, because policymaking under such governments is plagued by the so-called common-pool problem.

Despite its plausibility, this conjecture has not really been carefully studied, neither theoretically nor empirically. One reason may be that the suggested causal chain is quite complex. Rather than studying the entire chain, researchers have thus focused on only one or two of its links. Another reason for the lack of encompassing research may be that the issues fall in the cracks between two disciplines. Political scientists have studied the political consequences of alternative electoral rules and neglected their economic repercussions whereas economists have focused on their economic effects in simplified political settings where party structures and types of government are exogenous or play no significant role. ${ }^{3}$ The goal of this

\footnotetext{
${ }^{1}$ See, in particular, Milesi-Ferretti, Perotti and Rostagno, 2002, Persson and Tabellini 2003, 2004 and Persson, Tabellini and Trebbi, 2003.

${ }^{2}$ See, for instance, Laver and Schofield, 1990, Lijphart, 1984, 1994, 1999, Powell, 1982, 2000, and Taagepera and Shugart, 1989.

${ }^{3}$ Thus Cox $(1990,1997)$ focused on the link between electoral rules and the number of candidates or parties while neglecting government formation and policy; Austen-Smith (2000) studies taxation and government formation under alternative electoral rules, but takes party structures as exogenous; Baron and Diermeier (2001) study government formation and policymaking under
} 
paper is to mend these cracks by studying the effects of the electoral rule on political outcomes - party structures and types of government - as well as economic outcomes - fiscal policies and rents - in a common framework. ${ }^{4}$

We study the politico-economic interactions in parliamentary democracies as a multi-stage, extensive-form game. Making use of many simplifying assumptions, we solve this game for equilibrium party structures, types of government and economic policies under alternative assumptions about electoral rules and other parameters characterizing the economic and political environment. Our model rests on two key mechanisms. First, in party formation politicians trade off expected electoral gains from a larger party against the sharing of rents when holding office. Second, policy formation is driven by electoral conflicts: between the government and opposition (always), and the parties within government (under coalition governments).

Solutions of the model imply several sharp predictions for the joint effects of the electoral system on political outcomes and economic policy outcomes. We then take these predictions to the data, using political and economic data from up to 50 parliamentary democracies in the post-war period. Our estimates rely alternatively on the cross-country variation in the data, or the within-country variation associated with electoral reforms.

The central result of the paper, supported by both theory and evidence, is that majoritarian elections cause less government spending because, by leading to a less fragmented party system, they reduce the incidence of higher-spending coalition governments. Party fragmentation can persist under majoritarian rule, however, especially if constituencies for the different parties are unevenly distributed across electoral districts and create strong geographical heterogeneity in the electoral strength of different parties.

The next section (Section 2) presents and discusses our (many) assumptions about party formation, government formation, economic policy formation and the behavior of politicians and voters. We then solve the model and characterize the solution under a proportional electoral system (Section 3), as well as a majoritarian electoral system (Section 4). Following this, we extend the basic framework (Section 5) by introducing asymmetries and heterogeneity among economic and

PR, but also take party structure as exogenous; and Persson and Tabellini (1999, 2000) study the effects of electoral rules on a variety of policy outcomes, but always take party structure as given.

${ }^{4} \mathrm{~A}$ recent and very interesting paper by Bawn and Rosenbluth (2002), to which we owe considerable inspiration, has a similar ambition. 
political groups. Finally, we present (Section 6) our data and results from empirical tests of the theoretical predictions. Conclusions and suggestions for further work are collected at the end (Section 7).

\section{The model}

\subsection{Economic policy}

A population consists of 4 economic groups of equal size, normalized to unity and indexed by $J$. Individuals in group $J$ have preferences represented by:

$$
V^{J}(\mathbf{q})=1-\tau+H\left(g^{J}\right) .
$$

Here, $\tau$ is a lump sum tax constrained to be non-negative, $g^{J}$ is a local public good that only benefits economic group $J, H$ is a well-behaved concave utility function, and $\mathbf{q}$ denotes the full vector of policy instruments. Individual income is normalized to 1 for all individuals. The government budget constraint equates total tax revenue to total spending:

$$
4 \tau=\sum_{J} g^{J}+\sum_{P} r^{P}
$$

where $r^{P}$ denotes political rents (here, literally taken out of tax revenue) appropriated by political party $P$.

This is a simple and standard economic policy setting in the literature: see for instance Persson, Roland and Tabellini (2000), Persson and Tabellini (2000). The vector of policy instruments, $\mathbf{q}=\left[\tau,\left\{g^{J}\right\},\left\{r^{P}\right\}\right]$, induces a three-way conflict of interest: (1) among economic groups over the allocation of the (targeted) spending on local public goods, $\left\{g^{J}\right\} ;(2)$ between politicians and citizens at large over the total size of political rents, $\Sigma r^{P}$, versus (non-targeted) taxes, $\tau$; and, (3) among politicians over the allocation of these rents, $\left\{r^{P}\right\}$.

A benevolent and utilitarian social planner, who assigns no value to the rents captured by politicians, would implement the following policy (subscripts denote partial derivatives and ${ }^{-1}$ an inverse function):

$$
\hat{g}^{J}=H_{g}^{-1}(1), \quad \hat{r}^{P}=0
$$

with taxes residually determined from the government budget constraint (we assume an interior optimum). All groups are treated equally and the marginal 
utility of the local public good $g^{J}$ for a quarter of the population is equated to the opportunity cost of private consumption for the whole population, namely unity. Political rents are set at zero.

\subsection{The political system}

We model the political system as a multistage game. All stages take place within the single period described in the previous subsection (we discuss below how to extend the model to a multiperiod framework). We can think of this single period as the life of a legislature, beginning right after the preceding election and ending with a fixed election date. The legislature consists of four groups of legislators, each representing one of the economic groups discussed above.

The game has four consecutive stages: a party formation stage, when the four groups of legislators can either form group-specific parties, or merge into larger parties; a government formation stage, when a government supported by a legislative majority is formed; a policy formation stage, when the government (and its legislative majority) sets economic policy; an election stage, when citizens observe their welfare and vote for one of the existing parties. The rules of the game are always the same, except for the electoral rule: we compare equilibria under proportional and majoritarian elections. Before we delve into that comparison, the remainder of this section describes and discusses the extensive form of the game in each of its four stages.

\subsubsection{Party formation}

Just after the previous elections, each political group in the legislature has a simple choice: whether to form a separate group-specific party, or to merge into a new and larger party with another group. At the outset, the legislature thus consists of four political groups, numbered from 1 to 4, each representing one of the economic groups. The precise meaning of the word "representing" is explained when we describe the election stage, below. For simplicity, we assume that each political group has an initial seat share of $1 / 4$ (under suitable assumptions discussed below, the results can be generalized to arbitrary initial seat shares).

The decision whether to merge or (remain) split is made strategically by these groups, taking into account subsequent equilibrium outcomes. We simplify the strategy space by only allowing mergers between groups 1 and 2, and groups 3 and 4 respectively. This restriction could be justified by invoking ideological 
affinities, but we do not model these explicitly. For a merger to take place, both merging groups must agree; if not, they form separate parties. ${ }^{5}$

The outcome of this stage is a party system, where parties are indexed by $P$. If a party represents only one economic group, $J$, we index this party $P=J$. If two groups of legislators merge, the resulting party represents two economic groups, $I$ and $J$; and we write the party index as $P=I J$. Three outcomes are thus possible: a two-party system, $(P=12$ and $P=34)$, a four-party system $(P=1,2,3,4)$, and a three-party system $(P=12,3,4$, or $P=1,2,34)$. We let $N$ denote the equilibrium number of parties, and the possible outcomes by $N=I I, I I I, I V$.

Let ${ }_{N} W^{P}$ denote the expected payoff of party $P$, at the start of the next (government-formation) stage of the game, i.e., its continuation utility after party formation, once $N$ parties have formed. These payoffs are described more precisely below, except for the following natural assumptions: if political group $J$ remains a party on its own, its expected continuation payoff coincides with that of the group-specific party: ${ }_{N} W^{J}={ }_{N} W^{P}$, with $P=J$. If instead political groups $I$ and $J$ merge, each one expects to receive one half of the expected continuation payoff of the merged party ${ }_{N} W^{J}=\frac{1}{2}{ }_{N} W^{P}$, with $P=I J$.

A four-party system is an equilibrium if - taking into account the expected equilibrium outcome of subsequent stages - the groups of legislators representing economic groups $I$ and $J$ find it optimal to remain split, given that the other two groups have also decided to stay split, i.e., ${ }_{I V} W^{P}>\frac{1}{2}{ }_{I I I} W^{I J}$, for $P=I, J$. This condition must hold for $I$ and $J=1,2$ or 3,4. Equilibrium conditions for a two-party, or a three-party, system are formulated in an analogous way. ${ }^{6}$

\subsubsection{Government formation}

After party formation, but before any policy decisions, a government is formed. We keep this stage of the game as simple as possible, skipping any strategic interactions, by just postulating an exogenous stochastic process for government formation. Any government needs the support of at least half the legislature. In line with our assumptions about party formation, we only allow governing

\footnotetext{
${ }^{5}$ This assumption only matters when we introduce asymmetries: if the model is symmetric, the incentives to merge or remain split are the same for the pair contempleting a merger.

${ }^{6}$ The assumption of four primitive groups in the legislature is not restrictive. We could instead have assumed the initial legislature to consist of two or three parties, allowing them to splinter into smaller group-specific parties. Nothing of substance would change in this alternative formulation and the same set of equilibrium party systems would result with suitable changes in notation.
} 
coalitions, when relevant, between parties 1 and 2 , or between parties 3 and 4 . We thus rule out minority governments, as well as surplus coalitions, by assumption. Finally, we assume that a government is always formed and that each party is included in government with a probability equal to its seat share in the legislature, given the restrictions on feasible coalitions. ${ }^{7}$

At the end of the government formation stage, each party $P$ can thus be in one of three states, indexed by $G$ : outside of government $(G=O)$; in a coalition government $(G=C)$; or in a single-party government $(G=S)$. Given the rules of the game and the restrictions on feasible coalitions, the three indexes $(P, N, G)$ summarize all the relevant political outcomes up to this stage.

\subsubsection{Policy formation and payoffs}

Once a government has formed, the parties in government set economic policy. We start by describing their payoffs.

Parties are opportunistic: they care only about political rents in the current period and seats in the next legislature. Specifically, consider party $P$, with government status $G$ in a system with $N$ parties, and let ${ }_{N} W_{G}^{P}$ denote its expected payoff at the start of the policy formation stage. This continuation payoff is linked to that of the party formation stage by: ${ }_{N} W^{P}=\mathrm{E}\left({ }_{N} W_{G}^{P}\right)$, where the expectations operator $\mathrm{E}$ refers to the uncertainty in government formation. We assume:

$$
{ }_{N} W_{G}^{P}=r_{G}^{P}+E\left({ }_{N} s_{G}^{P}\right) R^{P}
$$

where $r_{G}^{P}$ denotes the rents captured by party $P$ in the current legislature and $R^{P}$ denotes the expected value of seats in the next legislature, ${ }_{N} s_{G}^{P}$ denotes the seat share of party $P$ in the next legislature, conditional on current government status $G$, and the expectations operator $E(\cdot)$ refers to the electoral uncertainty remaining at the policy formation stage. Note that current $(r)$ and future $(R)$ rents do not depend on the number of parties in the legislature, $N$. This is a feature of the equilibrium, that will be derived in the next section. But the expected seat share, $E\left({ }_{N} s_{G}^{P}\right)$, is indexed by $N$, because its equilibrium value does

\footnotetext{
${ }^{7}$ Taking minority governments seriously would require specifying a richer model of policy formation than the one coinsidered below. In particular, we would have to take into account the strategic interactions in the legislature, given the specific rules for government breakup and formation. Laver and Shepsle (1996) and Diermeier, Eraslan and Merlo (2003) provide detailed game-theoretic analyses of government formation, but neglect most of the remaining political interactions (party formation, policy formation, and elections).
} 
depend on the number of parties (at least under some electoral rules). ${ }^{8}$ Next we discuss the possible outcomes for $r_{G}^{P}$ and $R^{P}$, while $E\left({ }_{N} s_{G}^{P}\right)$ is discussed in the next subsection.

It is easy to show that the parties in government never find it optimal to confer any rents on the parties in opposition. Rather than deriving this result in every case studied below, we simply set $r_{O}^{P}=0$ in the following. The first term in (2.4) is thus relevant only for a party in government, i.e., for $G=C, S$.

The expected value of seats in the next legislature, $R^{P}$, is taken as given when policy is set in the current period, since it refers to future events beyond the control of the current government. But as we shall see, the value of seats matters not only for expected payoffs but also for current policy, in particular for the optimal size of current rents, $r_{G}^{P}$. To pin it down, we let $R^{P}$ be proportional to total equilibrium rents captured by the government, and we implicitly assume that the party structure remains the same after the election. The expected value of seats differs for a small party $(P=J)$ and a large party merging two political groups $(P=I J)$, because a small party can only be in a coalition government, while a large party can only be in a single-party government. Specifically, let $r_{G}^{* P}$ denote equilibrium rents captured by any individual party, conditional on being in a government of type $G=C, S$. Then we assume

$$
R^{P}=\left\{\begin{array}{c}
2 \gamma r_{C}^{* P} \\
\gamma r_{S}^{* P} \text { if } P \text { is small }(P=J) \\
\text { is large }(P=I J),
\end{array}\right.
$$

where $\gamma$ is a positive parameter measuring the payoff from future expected rents.

Thus, by (2.4) and (2.5), the parties want to win seats in the next legislature, because they are associated with a bigger expected share of future government rents. Although this formulation is quite plausible, we do not attempt to derive it from more primitive assumptions about bargaining over government formation in the next legislature. In this respect, we treat government formation as a black box in the present as well as future periods. ${ }^{9}$

\footnotetext{
${ }^{8}$ Note that we use different operators to denote expectations at the policy formation stage, $E(\cdot)$, and the party-formation stage, $\mathrm{E}(\cdot)$, since the nature of the uncertainty is different.

${ }^{9}$ Preserving some symmetry, the results derived in the next section, including the equilibrium party structure, hold for arbitrary seat shares in the initial legislature (and not just for equal initial shares among all parties). In this sense, the static equilibrium of this game is self-replicating, and the implicit assumption that the equilibrium party structure remains unchanged after the election is not too restrictive. Extending the model to an intertemporal set up, however, would raise deeper questions about the payoffs and the rules for government formation. We leave this extension for future research.
} 
We now turn to the extensive form of the policy formation stage. If a single party holds government, policy formation is straightforward: the party acts in unison and simply sets the vector of policy instruments q to maximize (2.4) subject to the economic constraints (2.1) and (2.2), and taking into account equilibrium behavior at the subsequent election stage, yet to be described.

In the event of a coalition government, the parties in government generally disagree over the allocation of spending on local public goods, $\left\{g^{J}\right\}$, and rents, $\left\{r^{P}\right\}$ - see below. We assume that each member of the coalition has unilateral decision making power over the relevant dimension of these two variables; thus, party $P$ representing economic group $J$ unilaterally sets rents for itself, $r^{P}$, and local public goods benefiting its group $J, g^{J}$, so as to maximize (2.4) subject to the economic constraints (2.1) and (2.2), and taking into account the equilibrium at the election stage. As we shall see, all coalition members agree about the optimal amount of spending on the local public goods benefiting the groups not represented in government. Hence, it is unimportant who has control over these policy instruments, and for simplicity we assume that a coin is tossed about who is entitled to choose them. Finally, we assume that tax revenues $\tau$ are residually determined so as to balance the budget, once all spending decisions have been made (assuming an interior optimum for the tax rate).

This assumption about the behavior of coalition governments can be interpreted as parties obtaining agenda-setting powers - say, in the form of ministerial positions - over the policy dimensions they care about the most (such powers could potentially be derived from bargaining over ministerial positions at a government formation stage, as in Laver and Shepsle, 1996). This agenda-setting power is strong enough to allow the minister in charge to do what is unilaterally optimal for her party. This would happen, for instance, if rejection of a policy proposal led to a government crisis or some very costly outcome for the coalition members, as in Diermeier and Feddersen (1998) or Persson, Roland and Tabellini (2000).

As discussed in the next section, the implication of our assumptions about policy formation is that coalition governments, but not single-party governments, face a common-pool problem in setting local public goods and rents.

\subsubsection{Elections and voters}

We assume that citizens vote retrospectively, based on "ideology", as well as their economic welfare, rewarding or punishing the incumbent government according to 
whether their individual utility is above or below a given reservation utility level. Ideology nevertheless plays a role in that they reward or punish the party representing their group differently than parties representing other groups. Specifically, citizen $i$ in group $J$ votes for party $J$ when it is in government if:

$$
V^{J}(\mathbf{q}) \geq \omega^{i}+\delta+V^{* J}
$$

If the inequality turns the other way, she votes for the opposition; if the opposition has more than one party, each opposition party receives her vote with equal probability. If party $J$ is not in government and if inequality (2.6) is satisfied, then in case there is a government coalition, each party in the coalition receives her vote with equal probability; if the inequality is not satisfied, she votes for her "own" party. Voters thus reward their own party more often than other parties ${ }^{10}$.

The first term on the right hand side of (2.6) depicts an individual component of reservation utility: $\omega^{i}$ is uniformly distributed within each group of voters, with mean zero and density $\phi$. Individuals with higher values of $\omega^{i}$ are more demanding of the incumbent government. The second term is a random shock to the popularity of the incumbent government, common to all voters. We assume that $\delta$ is also uniformly distributed, with mean 0 and density $\psi$. Thus, we can think of $\phi$ as a measure of within-group voter mobility, and $\psi$ as a measure of aggregate mobility between government and opposition (higher values correspond to higher mobility). The last term is given by $V^{* J}=V^{J}\left(\mathbf{q}_{G}^{*}\right)$, where $\mathbf{q}_{G}^{*}$ denotes the equilibrium policy vector, for a given party structure, a given type of government and a given electoral rule - as shown below, the number of parties in the legislature has no influence on equilibrium policy once we control for the type of government. It reflects the voters' expectations of what the government can reasonably be expected to deliver, given the political circumstances in which policy is set.

As we will see, these assumptions imply that in equilibrium on average half of the voters vote for the incumbent government while the remaining half votes for the opposition. When the incumbent government sets policy, it knows the distributions for $\omega^{i}$ and $\delta$, but not the realization of the aggregate popularity shock $\delta$. As in other probabilistic voting models, this uncertainty creates a smooth mapping from policy to expected vote shares.

\footnotetext{
${ }^{10}$ As we will see below, this behavioral assumption is important because it induces a conflict among parties in a coalition government. It creates an electoral incentive for a political party $P$ in government to please the group it represents, but not the group represented by the coalition partner.
} 
These specific assumptions about voting behavior can be generalized in several ways, without altering the nature of the results. Two specific aspects are central to our argument, however. First, voters are not fully intertemporally rational, and not modeled as strategic players. We are not too apologetic about ruling out strategic voting. Instances of this phenomenon may certainly be observed in the real world. Given the low individual stakes for a single, atomistic voter, however, sophisticated strategic voting is not necessarily more plausible than simple retrospective voting. On the other hand, we believe that it is much more important to model professional politicians as fully rational, strategic actors.

The second central aspect is that voters reward only their own party (rather than the whole coalition) when they are pleased with the government performance. Again, the specific way this behavior is modeled is not so important. The central idea is that at least some voters are ideologically attached to a party, and that their voting behavior discriminates between parties in a coalition government. But if the parties merge, voters become unable to discriminate between them. As stressed by Bawn and Rosenbluth (2002), the idea that voters can discriminate between parties in a coalition government, but not between groups inside a single party, may be at the core of why coalition governments behave differently than single-party majorities.

\subsubsection{Electoral rules}

When votes have been cast, they are translated into seats for the next legislature according to the electoral rule in place. Under proportional elections, all voters belong to a single national district, and the electoral formula is PR. Thus, each party receives a seat share in the next legislature directly proportional to its vote share in the national district. Under majoritarian elections, voters are distributed in a continuum of single-member districts indexed by $d$, and the electoral formula in each district is plurality rule. Thus, district $d$ has one seat in the next legislature, and the seat is won by the party with the highest vote share in $d$.

\subsubsection{Political-economic equilibrium}

A full politico-economic equilibrium is an equilibrium of this multi-stage game. More precisely, an equilibrium is:

a) a party system resulting from optimal choices by the primitive groups of legislators at the party formation stage, taking into account the electoral rule and the expected equilibrium outcomes at stages b)-d). 
b) a type of government (coalition or single-party majority) selected by nature at the government formation stage, given the equilibrium party system.

c) a policy optimally selected by the parties in each possible government, given the equilibrium party system and the type of government, and taking into account the electoral rule and the expected equilibrium outcome at stage d).

d) an election outcome, given the electoral rule, the equilibrium economic policy, type of government, and party system.

\section{Proportional elections}

Under proportional elections, the seat share of each party, ${ }_{N} s_{G}^{P}$, is identical to its nation-wide vote share, ${ }_{N} v_{G}^{P}$. In the first subsection, we compute the equilibrium economic policies under coalition governments and single-party governments, focusing on the last two stages of the game, elections and policy formation. In the next subsection, we characterize the equilibrium party system and the equilibrium type of government.

\subsection{Equilibrium policy}

\subsubsection{Coalition government}

Consider a four-party system $(N=I V)$. We assume (without loss of generality given the symmetry of the model) that parties 1 and 2 form a coalition government, while parties 3 and 4 make up the opposition. We first describe equilibrium vote shares and seat shares as a function of economic policy and then compute equilibrium policies.

Equilibrium seat shares Consider the voters in group $J=P$, where $P=1$ or 2 is one of the two parties in government. Pick a voter in this group, with a value of $\omega^{i}$ exactly equal to $V^{J}-V^{* J}-\delta$. By (2.6), this "swing voter" in group $I$ is just indifferent between voting for $P$ and voting (randomly) for an opposition party. All voters of the group with a lower value of $\omega^{i}$ vote for party $P$. Let $F(\cdot)$ denote the cumulative distribution function of $\omega^{i}$ in (2.6). The fraction of voters in group $J=P$ voting for party $P$ is thus $F\left(V^{P}-V^{* P}-\delta\right)$, while the complementary fraction $1-F\left(V^{P}-V^{* P}-\delta\right)$ votes (randomly) for the opposition.

The vote share, and hence also the seat share, for each of the parties in the coalition government $(P=1,2)$ is: 


$$
{ }_{I V} v_{C}^{P}=s_{C}^{P}=\frac{1}{4}\left[F\left(V^{P}-V^{* P}-\delta\right)+\frac{1}{2} \sum_{J=3}^{4} F\left(V^{J}-V^{* J}-\delta\right)\right]
$$

Among the terms between square brackets, the first reflects the share of voters in group $P$ whose reservation utility is satisfied, and the second the share of satisfied voters from other groups $(J=3,4)$. As the latter split their vote equally between the two parties in the governing coalition, the second term is multiplied by $1 / 2$. Finally, since each economic group constitutes one quarter of the population, the whole expression is pre-multiplied by this number.

As $\omega^{i}$ has the same uniform distribution in each group, $F(\omega)=\frac{1}{2}+\phi \omega$. Recall also that the expected value of the popularity shock $\delta$ is zero, at the time policy is set. After some simplifications, the expected seat share in the next legislature for party $P$ reduces to:

$$
E\left({ }_{I V} s_{C}^{P}\right)=\frac{1}{4}+\frac{\phi}{4}\left[\left(V^{P}-V^{* P}\right)+\frac{1}{2} \sum_{J=3}^{4}\left(V^{J}-V^{* J}\right)\right] .
$$

Thus, the expected seat share in the next legislature depends linearly on the weighted indirect utilities of the voters from $J=P$ and from the opposition parties. As mentioned above, the density $\phi$ of the idiosyncratic reservation utilities measures within-group mobility and hence the response of the expected seat shares to economic policy. Note that the groups represented by a party in government receive twice the weight of the groups in the opposition. Finally, whatever the equilibrium policies at the policy formation stage, $V^{J}=V^{* J}$, by definition of $V^{* J}$. Equation (3.2) thus immediately implies that the expected equilibrium seat share in the next legislature for a coalition partner, at the party formation stage is $\frac{1}{4}$. Thus, in the expected equilibrium continuation payoff ${ }_{I V} W_{C}^{P}$, given by $(2.4)$ above, we will be able to set $E\left({ }_{I V} s_{C}^{P}\right)=\frac{1}{4}$. By the symmetry of the model, the expected seat share at the party formation stage for a small party in opposition is exactly the same; i.e., in ${ }_{I V} W_{O}^{P}$ we set $E\left({ }_{I V} s_{O}^{P}\right)=\frac{1}{4}$.

What would happen if the opposition instead consisted of a single party? It is easy to verify that the expressions for the expected vote shares for government coalition parties at the party formation stage are exactly the same: i.e., we have $E\left({ }_{I V} s_{C}^{P}\right)=E\left({ }_{I I I} s_{C}^{P}\right)=\frac{1}{4}$ for $P=1,2$. A single opposition party can expect to capture the remaining votes $E\left({ }_{I I I} s_{O}^{P}\right)=\frac{1}{2}$. 
Equilibrium policy Party $P=1,2$ in a coalition government sets $r^{P}$ and $g^{J}$, $J=P$, so as to maximize (2.4), subject to (3.2), (2.1) and (2.2), and for a given value of future seats $R^{P}$. Since both parties in the coalition government agree over spending benefiting the groups not represented in government, it is irrelevant who sets it; we thus let either of $P=1,2$ optimize with regards to $g^{J}, J \neq 1,2$. Moreover, the policymaking incentives are identical independently of whether the opposition consists of on or two parties (in the previous section we could omit the back subscript $N$ from policy outcomes, because they are the same irrespective of $N$, given the type of government).

The resulting optimality conditions for spending imply: ${ }^{11}$

$$
g_{C}^{* J}=\left\{\begin{array}{ccc}
H_{g}^{-1}\left[\frac{1}{2}\right] & \text { if } & J=1,2 \\
H_{g}^{-1}[1], & \text { if } & J=3,4
\end{array}\right.
$$

Retrospective voting induces opportunistic politicians to enact a suboptimal allocation of local public goods, relative to the choices of a social planner. The groups represented in government have an advantage, and spending on the local public good benefiting them exceeds the social optimum: $g_{C}^{* J}>\hat{g}^{J}=H_{g}^{-1}(1), J=1,2$. Intuitively, the disproportionate electoral response by its own voters induces each party in government to give them more weight. Since coalition members chose local public goods unilaterally, we have a common-pool problem: the necessary financing comes out of taxes levied on all groups, and the electoral losses from this are also borne by the coalition partner. This leads both parties in government to overspend on their constituencies. Conversely, the economic groups not represented in government $(J=3,4)$ receive the efficient amount of public goods although they pay higher than optimal taxes. Intuitively, the parties in government agree to give less weight to groups 3 and 4 because electoral support in these groups is less sensitive to their welfare compared to one's "own" constituency.

It remains to determine the rents extracted by each party. In deciding on $r^{P}$, party $P$ trades off the direct gain of higher rents today against the loss of a lower expected seat share (recall that the future value of office is taken as given by the party). The optimum condition can be written:

$$
1+R^{P} \frac{\partial E\left(I V s_{C}^{P}\right)}{\partial r^{P}}=0
$$

\footnotetext{
${ }^{11}$ In deriving (3.3), we use (2.1) and (2.2) which imply that $\frac{\partial V^{J}}{\partial g^{I}}=H_{g}\left(g^{J}\right)-1 / 4$ for $I=J$, and $\frac{\partial V^{J}}{\partial g^{I}}=-1 / 4$ for $I \neq J$.
} 
$>$ From (2.5) and the fact that $P$ is a small party, we have $R^{P}=\gamma 2 r_{C}^{* P}$. Imposing the consistency condition that future and current equilibrium rents (per party) are the same, and using (3.2), we can solve (3.4) for the equilibrium rents captured by each party in a coalition government: ${ }^{12}$

$$
r_{C}^{* P}=\frac{4}{\gamma \phi} .
$$

Thus, equilibrium rents tend to be higher: (i) the smaller is the relative weight, $\gamma$, assigned to future rents; (ii) the lower is within-group mobility, $\phi$, and hence the responsiveness to welfare losses among voters.

Total equilibrium rents in a coalition government are given by

$$
r_{C}^{*}=\sum_{P=1}^{2} r_{C}^{* P}=\frac{8}{\gamma \phi} .
$$

\subsubsection{Single-party government}

Given the symmetry of the model, it does not matter for the policies chosen by the single-party majority whether its opposition consists of a single party or two distinct parties. Thus, the results presented in this section refer to a two-party system, as well as a three-party system. Thus, we omit the $N$ back subscript, whenever there is no risk of confusion.

Equilibrium seat shares To fix ideas, consider the choices by party $P=12$, resulting from the merger of legislative groups 1 and 2, when in government. Compared to a party in coalition government, this large party twice as large a vote share among its own voters (now groups 1 and 2) and among the opposition groups. Its seat share and vote share is thus given by an expression similar to (3.1) above:

$$
s_{S}^{P}=v_{S}^{P}=\frac{1}{4}\left[2+\sum_{J=1}^{4} F\left(V^{J}-V^{* J}-\delta\right)\right] .
$$

\footnotetext{
${ }^{12}$ Here, we used the result that $\frac{\partial V^{J}}{\partial r^{P}}=-1 / 4$ for all $J$. Note that here we pin down equilibrium rents through our assumption that current and future equilibrium rents are equal. But similar results would be obtained if we took the expected value of seats as parametrically given by $R^{P}$, and assumed that the parties' marginal utility of rents was strictly decreasing (rather than constant as assumed here).
} 
Repeating the same steps as in section 3.1.1, we can rewrite the expected seat share of party $P=12$ in the next legislature, given that it forms a single-party government today, as:

$$
E\left(s_{S}^{P}\right)=\frac{1}{2}+\frac{\phi}{4} \sum_{I=1}^{4}\left(V^{J}-V^{* J}\right) .
$$

As before, the expected seat share is a linear function of the weighted utilities of all the voters, but now all economic groups receive the same weights.

It is easy to see that in equilibrium the expected seat share for the party in government at the party formation stage entering the continuation payoff, ${ }_{N} W_{S}^{P}$ must be $E\left(s_{S}^{P}\right)=\frac{1}{2}$, since in equilibrium $V^{J}=V^{* J}$ for all $J$. By symmetry, $\frac{1}{2}$ is also the expected equilibrium seat share of a single party in opposition. If the opposition has two parties, they split the remaining expected equilibrium seats equally; i.e., $E\left({ }_{I I I} s_{O}^{P}\right)=\frac{1}{4}$ in ${ }_{I I I} W_{O}^{P}$

Equilibrium policy When the government is supported by a single party, conflicts of interest inside the government disappear, because voters can only punish or reward the party in government. Whereas they could discriminate between party 1 and party 2 in a coalition government, such discrimination is no longer possible between the groups of legislators forming the large party. Even though the voters of groups 1 and 2 still have conflicting interests, this conflict remains latent in policy formation. ${ }^{13}$

Specifically, equilibrium policy now results from the maximization of $(2.4)$ with regard to all policy instruments, subject to (2.1), (2.2), and (3.6), taking the value of expected future seats, $R^{P}$ as given. Repeating the steps in section 3.1.1, the optimality conditions imply:

$$
g_{S}^{* J}=H_{g}^{-1}(1), \quad J=1, . ., 4 .
$$

Comparing (3.7) and (3.3), we find that the overspending on groups represented in government disappears. Intuitively, the type of government matters for spending

\footnotetext{
${ }^{13}$ If politicians were not opportunistic, but instead motivated directly by all aspects of policy (e.g., as "citizen candidates"), there would be a conflict between the legislators inside a singleparty government. But the differences between single-party and coalition governments induced by voting behavior would still remain. With conflicting interests between legislators in merged parties, it would also be central to model within-party bargaining (and its differences from within-coalition bargaining).
} 
because coalition governments are subject to an electoral common-pool problem, whereas single-party governments are not. As noted above, the reason is that the voters must now treat the single party as an entity.

Finally, consider equilibrium rents. Taking as given the value of future seats and maximizing the single government's payoff, gives the following optimality condition:

$$
1+R^{P} \frac{\partial E\left(s_{S}^{P}\right)}{\partial r^{P}}=0
$$

Using $R^{P}=\gamma r_{S}^{* P}$ and (3.6), and imposing the condition that future and current equilibrium rents are the same, it is easy to show that equilibrium rents in a singleparty government are given by the same expression as (3.5): $r_{S}^{* P}=r_{C}^{* P}$. But as $r_{C}^{* P}$ denote the rents per party, total rents with a single-party government are half of those with a coalition government: $r_{S}^{*}=\frac{1}{2} r_{C}^{*}$. This stark result is due to the fact that a single-party government internalizes all the electoral costs of rent extraction, whereas each party in a coalition internalizes only half the electoral costs and sets policy unilaterally, ignoring the electoral costs of its coalition partner.

We can summarize the above discussion as follows:

\section{Proposition 1}

In a proportional electoral system, the overall size of government, as measured by total taxes, is larger under coalition governments than under single-party governments. Coalition governments spend more on programs favored by the groups represented in government and collect larger political rents than single-party governments. Spending on programs favored by opposition groups are the same under the two types of government.

\subsection{Equilibrium party structure}

Having determined equilibrium economic policy under both types of government, we turn to the first two stages of the game: party formation and government formation.

\subsubsection{Government formation}

We need to determine the equilibrium expected payoffs of the parties represented in the legislature at the outset of the government formation stage for all possible party systems. 
Four party system Suppose that the legislature consists of four parties $P=$ $1,2,3,4$. Given the rules of government formation, only coalition governments are possible in this case: coalitions of parties 1 and 2, and 3 and 4, are formed with the equal probability, $\frac{1}{2}$.

By (2.4), the expected utility for any of these parties, at the start of the government formation stage, is thus:

$$
{ }_{I V} W^{P}=\mathrm{E}\left({ }_{I V} W_{C}^{P}\right)=\frac{1}{2}\left[r_{C}^{P}+E\left({ }_{I V} s_{C}^{P}\right) R^{P}\right]+\frac{1}{2}\left[E\left({ }_{I V} s_{O}^{P}\right) R^{P}\right] .
$$

With probability $1 / 2$, party $P$ is in a coalition government in the current period, earning an expected utility given by the first square-bracketed term; with probability $1 / 2$, the party is out of government in the current period, earning expected utility given by the second term.

We established in the previous section that, in a four-party system, $E\left({ }_{I V} s_{C}^{P}\right)=$ $E\left({ }_{I V} s_{O}^{P}\right)=1 / 4$. As seen from the government formation stage, the expected equilibrium votes share is the same for the parties in government and opposition. Using the expression in (2.5) for the expected value of seats in the next legislature, $R^{P}$ and the expression in (3.5) for equilibrium rents, $r_{C}^{* P}$, the right hand side of (3.9) simplifies to:

$$
{ }_{I V} W^{P}=\frac{1}{2}(1+\gamma) r_{C}^{* P}=\frac{2(1+\gamma)}{\gamma \phi} .
$$

Two party system Instead suppose that the legislature consists of two parties, $P=12,34$. Only single party governments are possible, with equal probabilities, $1 / 2$. By (2.4), the expected utility of a generic party $P$, at the start of the government formation stage, is:

$$
{ }_{I I} W^{P}=\mathrm{E}\left({ }_{I I} W_{S}^{P}\right)=\frac{1}{2}\left[r_{S}^{P}+E\left({ }_{I I} s_{S}^{P}\right) R^{P}\right]+\frac{1}{2}\left[E\left({ }_{I I} s_{O}^{P}\right) R^{P}\right] .
$$

The first term is the expected utility of party $P$ when in government, in the current period, and the second term is its expected utility when out of government.

We established in the previous section that $E\left({ }_{I I} s_{C}^{P}\right)=E\left({ }_{I I} s_{O}^{P}\right)=\frac{1}{2}$. Carrying out the same kind of calculation as in the four-party system, the right hand side of (3.11) simplifies to:

$$
{ }_{I I} W^{P}=\frac{1}{2}[1+\gamma] r_{S}^{* P}=\frac{2(1+\gamma)}{\gamma \phi},
$$


which is exactly the same expression as in the four-party case. This should not come as a surprise. As shown in the previous section, the rents appropriated in equilibrium by each party in government are exactly the same, $r_{C}^{* P}=r_{S}^{* P}$. Moreover, the probability of being included in government is the same $\left(\frac{1}{2}\right)$, as is the expected value of future rents. Future expected rents are the same because the higher expected seat share of a single party, $E\left({ }_{I I} s_{S}^{P}\right)=\frac{1}{2}=2 E\left({ }_{I V} s_{C}^{P}\right)$, is exactly compensated by the lower value of total future rents accruing to a single party government, $r_{S}^{*}=\frac{1}{2} r_{C}^{*}$.

Three party system Finally, consider a three-party legislature, say $P=12$, 3 and 4 . Then both a single-party government and a coalition government are possible, with equal probabilities, $1 / 2$. Here the parties differ, and we have to keep track of their identity. The large party, $P=12$, can only be in a single-party government. As argued in Section 3.1, however, equilibrium rents for a singleparty government, $r_{S}^{* P}$, do not depend on the number of parties in the opposition, and neither does the value of future seats, $R^{P}=r_{S}^{*}$. Moreover, the expected seat share of a large party is always equal to $1 / 2$, irrespective of the number of parties in the legislature. Thus it follows that the expected payoff of a large party is the same as in the two-party system, ${ }_{I I I} W^{P}={ }_{I I} W^{P}$, for $P=12$, as given by the expression in (3.12). By similar reasoning, the smaller parties, $P=3$, 4, can only be in a coalition government, and their expected payoff is the same as in a four-party system ${ }_{I I I} W^{P}=_{I V} W^{P}$ as given by the expression in (3.10). All in all, the number of parties represented in the legislature does not matter for the parties' expected payoffs.

\subsubsection{Party formation}

It is now straightforward to compute the equilibrium of the party formation stage. As we have just seen, the expected equilibrium payoffs for parties are the same independently of the number of parties in the legislature: each party formed during the course of the party formation stage always has a continuation utility given by both (3.12) and (3.10). But this payoff accrues entirely to the members of legislative group $J$ if it forms a group-specific party, while it is divided in half between two groups merging into a large party. Therefore, no party will ever want to merge. Indeed, remaining split is a dominant strategy at the party formation stage. Applying the equilibrium conditions in Section 2.2.1, a four-party system is thus the unique equilibrium of the game under proportional elections. 
We thus have:

\section{Proposition 2}

In a proportional electoral system, the unique equilibrium outcome has four parties represented in the legislature. As a result, only coalition governments are observed.

The fact that small parties in coalition governments extract as much rents as large parties in single-party governments keep parties from merging. Note that the electoral rule plays an important role here: as PR makes vote shares equal to seat shares, merging yields no particular advantage by extending the voter base. As we shall see in the next section, this is no longer the case under plurality rule. Note also that the model suggests that it may be hard to test the prediction in Proposition 1 about the behavior of coalition and single-party governments under proportional elections. In the model the prediction concerns an unobserved counterfactual: by Proposition 2, we should not observe any single-party governments under proportional elections. Of course, the model is very symmetric and simple, and with enough asymmetries, say in the seat shares of voters across economic groups, or in the size of the groups, we may be able to generate equilibria with two or three parties - see Section 5 below.

\section{Majoritarian elections}

Under majoritarian elections, the population is divided in a continuum of singlemember electoral districts. Each of these districts carries out a plurality-rule election where the party winning the largest vote share wins the single seat. In the event of a tie in a district, a coin is tossed between the parties with the same vote share. In this section, we assume that the distribution of economic groups is the same in all districts. But this assumption is relaxed in Section 5.

\subsection{Equilibrium policy}

\subsubsection{Coalition government}

Equilibrium seat shares Suppose that parties 1 and 2 are in a coalition government. Equilibrium vote shares, $v^{P}$, are still given by (3.1) in the previous section, which relates votes to government policy and the popularity shock, $\delta$. But now the formula for translating votes into seats is plurality rule. Because of the model's symmetry including the effects of the single random shock $\delta$, the 
two parties in government always have the same vote share in equilibrium: equation (3.1) implies that ${ }_{N} v_{C}^{1}={ }_{N} v_{C}^{2}$. Moreover, since all electoral districts are homogenous, either the two parties in government win the whole legislature, or the opposition wins the whole legislature, depending on the realization of $\delta$. If the two parties in government win, a coin is tossed to award the seat to one of them district by district. With a continuum of districts, in equilibrium each winning party in government ends up with half the seats in the legislature. ${ }^{14}$

This argument implies that the equilibrium expected seat share of party $P=$ 1,2 in a coalition government, is:

$$
E\left({ }_{N} s_{C}^{P}\right)=\frac{1}{2} \operatorname{Prob}\left[{ }_{N} v_{C}^{P} \geq{ }_{N} \bar{v}_{C}\right]
$$

where ${ }_{N} \bar{v}_{C}$ denotes the minimum threshold needed to win the election in any one of the identical districts given the number of parties. As before, the expectation and the probability refers to the uncertainty regarding the realization of $\delta$. If the opposition is also split in two parties (i.e., $N=I V$ ), we have ${ }_{I V} \bar{v}_{C}=\frac{1}{4}$. To win, the coalition parties in government thus need to carry at least half the votes in any district; since the votes are split equally between them (as they are between the opposition parties), any one of the parties in government needs to win a quarter of the votes in any district. If instead the opposition consists of a single party (i.e., $N=I I I),{ }_{I I I} \bar{v}_{C}=\frac{1}{3}$. As the vote for the government is split in half between the coalition parties, the government parties win the elections only if each of them has a vote share at least as large as that of the single opposition party.

Recall that the random variable $\delta$ has a uniform distribution with mean 0 and density $\psi$. Using (3.1) and simplifying, we then obtain the expected seat share in the next legislature, at the policy formation stage, for a party in a coalition government:

$$
\begin{aligned}
E\left({ }_{N} s_{C}^{P}\right)= & \frac{1}{4}+\left(\frac{1}{4}-{ }_{N} \bar{v}_{C}\right) \frac{\psi}{\phi}+ \\
& +\frac{\psi}{4}\left[\left(V^{P}-V^{* P}\right)+\frac{1}{2} \sum_{J=3}^{4}\left(V^{J}-V^{* J}\right)\right] .
\end{aligned}
$$

This expression is similar to that under proportional elections, equation (3.2). The differences are that: (i) the density $\phi$ of the idiosyncratic reservation utility

\footnotetext{
${ }^{14}$ The reader may wonder why, then, the coalition parties do not strategically agree to split the districts among themselves running only a single coalition candidate in each district. But in our simple model, these agreements would not be self-enforcing. To satisfactorily address this issue, a richer model is needed.
} 
$\omega^{i}$ is replaced in the third term (4.2) by the density $\psi$ of the popularity shock $\delta$; (ii) the constant in (4.2) depends on the number of parties in the opposition, through the second term in ${ }_{N} \bar{v}_{C .}{ }^{15}$

Whatever the equilibrium policies at the policy formation stage, we have $V^{J}=$ $V^{* J}$. As explained above, in a four party system we have ${ }_{I V} \bar{v}_{C}=1 / 4$. Hence, the equilibrium seat share in the next legislature expected by each coalition partner at the party formation stage is $E\left({ }_{I V} s_{C}^{P}\right)=\frac{1}{4}$. By the symmetry of the model, this is also the expected seat share of each of the two parties in the opposition, $E\left({ }_{I V} s_{O}^{P}\right)=$ $\frac{1}{4}$. In a three party system, ${ }_{I I I} \bar{v}_{C}=1 / 3$. Here, the expected equilibrium seat share of each small party $(P=1,2)$ when in government is:

$$
E\left({ }_{I I I} s_{C}^{P}\right)=\frac{1}{4}-\frac{1}{12} \frac{\psi}{\phi},
$$

while the single party in the opposition has an expected seat share of $2(1-$ $\left.E\left({ }_{I I I} s_{C}^{P}\right)\right)$, namely:

$$
E\left({ }_{\text {III }} s_{O}^{P}\right)=\frac{1}{2}+\frac{1}{6} \frac{\psi}{\phi} .
$$

These two expressions illustrate an important difference between majoritarian and proportional elections, where we had $E\left({ }_{I I I} s_{C}^{P}\right)=\frac{1}{4}$ and $E\left({ }_{I I I} s_{O}^{P}\right)=\frac{1}{2}$. In terms of expected seats, plurality rule implies an extra gain for a large party, and an extra loss for a small party. This disproportionality effect raises the incentives to merge into large parties under majoritarian elections. ${ }^{16}$

Finally, note that the term ${ }_{N} \bar{v}_{C}$ enters additively in the right hand side of (4.2). Hence, the partial derivatives of $E\left(s^{P}\right)$ with respect to the policy instruments do not depend on $\bar{v}$. This implies that the optimal policy choices of a coalition government do not depend on the number of parties in the opposition, even though its equilibrium expected seat share does.

\footnotetext{
${ }^{15}$ Note that (4.2) gives us the equilibrium expected seat share: it was derived from (4.1), under the assumption that the vote shares of the two parties in government are equal, so that the seats gained by the whole coalition are split in half between them. Out of equilibrium, the coalition partner with more votes gets all the seats accruing to the coalition, and his expected seat share is given by the right hand side of (4.2) pre-multiplied by 2 . We return to this point when deriving the equilibrium policies in the next subsection, since there we also evaluate out-of-equilibrium payoffs.

${ }^{16}$ Since the expected seat shares must always lie between 0 and $1,(4.3)$ and (4.4) imply that $1 \geq \frac{\psi}{3 \phi}$.
} 
Equilibrium policies Consider first targeted government spending. When setting these policy instruments, each coalition member $P$ maximizes its expected seat share, $E\left({ }_{N} s_{C}^{P}\right)$, as given by (4.2), taking as given the equilibrium policies set by its partner. As we have seen, the weights of the different voters in (4.2) are the same as under proportional elections - cf. (3.2). This means that the allocation of equilibrium targeted spending coincides with that under proportional elections. In equilibrium, a coalition government under majoritarian elections thus sets $g_{C}^{J}$ according to (3.3) in Section 3.1.1. In other words, when electoral districts are homogenous, coalition governments make the same spending decisions, independently of the electoral rule. ${ }^{17}$

Next, consider the choice of political rents. Here, the electoral rule has a direct effect on equilibrium policy. Following the same approach as in Section 3.1.1, the first order conditions for equilibrium rents are still given by (3.4). But the trade-off between rents and expected seats is somewhat different. Imposing the condition that future equilibrium rents and current equilibrium rents are the same, and using (3.4) and (4.2), we obtain equilibrium rents captured by each party in a coalition government under majoritarian elections ${ }^{18}$ :

$$
r_{C}^{* P}=\frac{4}{\gamma \psi}
$$

Comparing this expression and the corresponding one under proportional elections, equilibrium rents in the two systems depend on the relative magnitude of $\phi$ and $\psi$. Without additional assumptions on these parameters, we cannot tell how the electoral rule shapes political rents. We can think of each of these density parameters as measuring the inverse of the variability in the distribution expressed in units of reservation utility. Because a uniformly distributed variable with density $\theta$ has variance proportional to $\frac{1}{\theta^{2}}$, we know that $\frac{\psi}{\phi}=\frac{\operatorname{Std}(\omega)}{\operatorname{Std}(\delta)}$. It follows from

\footnotetext{
${ }^{17}$ To be precise: when party $P$ chooses $g^{I}, I$ being a group in the opposition, the effect on his vote share and on that of his coalition partner are the same. Hence, to maximize his expected vote share, he maximizes the right hand side of (4.2). But when choosing $g^{J}$, party $P=J$ maximizes the right hand side of (4.2) multiplied by 2 , since the effect on his vote share can differ from that on his coalition partner's vote share - cf. footnote 15 . This change in the objective function does not affect the first order conditions that define the optimal policy, however, and thus has no behavioral implications.

${ }^{18}$ Recall that, by the government budget constraint, higher rents grabbed by party $P$ imply exactly the same loss of votes for both coalition partners. Hence, the remark in footnotes 15 and 17 do not apply, and it is correct to evaluate the effect of higher rents on expected seats on the basis of (4.2), as we have done.
} 
(3.5) and (4.5) that rents are more likely to be higher under proportional elections, the higher is the standard deviation of reservation utility within economic groups relative to the standard deviation of the popularity shock. As mentioned above, the latter is negatively related to aggregate mobility across parties, while the former is negatively related to within-group mobility. Summarizing, more aggregate mobility and less within-group mobility make more likely higher rents under proportional elections.

\subsubsection{Single-party government}

Equilibrium seat shares Let us compute equilibrium seat shares and policies for a government supported by a single-party majority, say $P=12$.

As in the case of coalition government, the electoral formula makes a difference. The single-party incumbent wins the whole legislature if its vote share is bigger than some threshold ${ }_{N} \bar{v}_{S}$ that depends on the number of parties in the opposition. Thus, the expected seat share in the next legislature for the single party in government is:

$$
E\left({ }_{N} s_{S}^{P}\right)=\operatorname{Prob}\left(v^{P} \geq{ }_{N} \bar{v}_{S}\right)
$$

If the opposition is also made up by a single party, then we have ${ }_{I I} \bar{v}_{S}=\frac{1}{2}$; if instead the opposition is split in two parties, we have ${ }_{I I I} \bar{v}_{S}=\frac{1}{3}$.

Using the distributional assumptions on the random popularity shock and (3.1), we can rewrite the expected seat share of the single party in government as:

$$
E\left({ }_{N} s_{S}^{P}\right)=\frac{1}{2}+\left(\frac{1}{2}-{ }_{N} \bar{v}_{S}\right) \frac{\psi}{\phi}+\frac{\psi}{4} \sum_{J=1}^{4}\left(V^{J}-V^{* J}\right) .
$$

Once more, the expression for the expected seat share is similar to that already derived for the single-party government under proportional elections, equation (3.6), and the term ${ }_{N} \bar{v}_{S}$ enters as a constant, so the number of parties in the opposition does not influence policy decisions.

The equilibrium expected seat share in the next legislature for the incumbent does depend on the number of parties in the opposition, however. In a two-party system, ${ }_{I I} \bar{v}_{S}=\frac{1}{2}$, and the equilibrium expected seat share at the party formation stage is the same for both parties: $E\left({ }_{I I} s_{S}^{P}\right)=E\left({ }_{I I} s_{O}^{P}\right)=\frac{1}{2}$. In a three-party system, with a single party in government and two parties in the opposition, ${ }_{I I I} \bar{v}_{S}=\frac{1}{3}$. Equation (4.6) then implies that the incumbent (large) party has an 
equilibrium expected seat share given by (4.4) above, while each one of the small parties in the opposition has an equilibrium expected seat share equal to (4.3) above.

Equilibrium policies As for coalition governments, it is easy to verify that targeted spending on public goods is not affected by the electoral rule, once we control for the type of government. Specifically, the equilibrium expressions for $g_{S}^{J}$ are identical to those in (3.7) for a single-party government under proportional elections. Combining this with the earlier results for coalition governments, we thus have a sharp and testable prediction: only the type of government, and not the electoral rule shapes government spending on public-goods programs. Once we hold constant the type of government, the electoral rule should have no independent influence on this aspects of fiscal policy.

Political rents collected by single-party governments do depend directly on the electoral rule, however, as in the case of coalition government. Repeating the steps in the previous subsection, it is easy to verify that $r_{S}^{* P}=r_{C}^{* P}$, where the latter is given by (4.5). Thus, a single party in government collects the same equilibrium rents as each member of a coalition government, so that total political rents are half of those collected under coalition government, just as it was the case under proportional elections. The ambiguity over which electoral rule generates more or less rents remains.

We summarize the foregoing discussion as follows:

\section{Proposition 3}

(i) Equilibrium public spending only depends on the type of government (coalition vs. single party), as described by Proposition 1, and not on the electoral rule or the number of parties in the opposition.

(ii) Equilibrium rents collected by each party in government only depend on the electoral rule, not on the type of government or the number of parties in the opposition. Under both electoral rules, total political rents collected by coalition governments are higher than the rents collected by single-party governments. The effect of the electoral rule on equilibrium rents is ambiguous, but greater withingroup voter mobility and smaller aggregate voter mobility make higher rents under proportional elections more likely. 


\subsection{The equilibrium party system}

We now turn to party formation and government formation under majoritarian elections.

\subsubsection{Government formation}

We start by computing equilibrium expected payoffs at the start of the government formation stage, for all possible party systems.

Four party system Suppose that we have four parties $(N=4): P=1,2,3$, and 4. The government can either be a coalition of parties 1 and 2 , or of parties 3 and 4 , with equal probabilities. Moreover, as shown in section 4.1.2, $E\left({ }_{I V} s_{C}^{P}\right)=$ $E\left({ }_{I V} s_{O}^{P}\right)=\frac{1}{4}$. The expected payoff for any party $P$, at the start of the government formation stage follows from (2.4) and (2.5):

$$
{ }_{I V} W^{P}=\frac{1}{2}[1+\gamma] r_{C}^{* P}=\frac{2(1+\gamma)}{\gamma \psi},
$$

where the right-most expression follows from (4.5).

Two party system In the case of two parties $(N=2), P=12$ and 34 ,only single-party governments are possible, both with equal probabilities, $1 / 2$. Their expected seat share in the next legislature are the same in government and opposition $E\left({ }_{I I} s_{S}^{P}\right)=E\left({ }_{I I} s_{O}^{P}\right)=\frac{1}{2}$. By $(2.4),(2.5)$ and (4.5), we compute their expected payoff as:

$$
{ }_{I I} W^{P}=\frac{1}{2}[1+\gamma] r_{S}^{P}=\frac{2(1+\gamma)}{\gamma \psi} .
$$

As with proportional elections, this turns out to be exactly the same expression as in the four-party case above (4.7). The intuitive explanation is also the same, namely a higher expected vote share is balanced by lower expected rents.

Three party system Finally, suppose we have a legislature with three parties $(N=3)$, say $P=12,3$ and 4 . Then, both single-party governments and coalition governments are possible, with equal probabilities, 1/2. But the expected equilibrium payoffs are no longer the same for all parties in the legislature.

Consider first the large party, $P=12$. Its expected payoff is still given by (3.11). But, as shown in the previous subsection, the expected seat share of the 
large party is larger than $1 / 2$, and given by (4.6). Using (2.5) and (4.5), his expected payoff simplifies to:

$$
{ }_{I I I} W^{P}=\frac{2(1+\gamma)}{\gamma \psi}+\frac{2}{3 \phi}, P=12 .
$$

Next, consider the two smaller parties, $P=3$, 4. Again, their expected payoffs at the start of the government formation stage are the same as in (3.9). But their expected seat share in the next legislature is now given by (4.3). Using (2.5) and (4.5), the equilibrium expected payoffs of the small parties simplify to:

$$
{ }_{I I I} W^{P}=\frac{2(1+\gamma)}{\gamma \psi}-\frac{2}{3 \phi}, \quad P=3,4 .
$$

Of course, this difference between the expected welfare of the small and large parties in a three-party system reflects the extra electoral bonus for a large party facing two small parties that we discussed in Section 4.1 .

\subsubsection{Party formation}

We now turn to the party formation stage. As we shall see, there is no universally dominant strategy for the four existing groups. Because of this, we can find conditions for two-party equilibria as well as four-party equilibria, while threeparty equilibria are ruled out by symmetry.

Specifically, we have a four-party equilibrium if all groups of legislators prefer to remain split rather than to merge, given two group-specific parties on the opposition side. More precisely, using the above notation, a four-party system is an equilibrium if, say,

$$
{ }_{I V} W^{1} \geq \frac{1}{2}{ }_{I I I} W^{12} .
$$

The left-hand side of (4.11) is the expected payoff of party(=group) 1 in a fourparty system. The right-hand side of (4.11) is the expected payoff accruing to group 1 if it merges with party 2 , given that the opponents have remained split: the term ${ }_{I I I} W^{12}$ is the expected payoffs of the large party $P=12$ in a three-party system, divided equally between the merging groups. Given the symmetry of the model, if condition (4.11) holds for party $P=1$, it also holds for all the other parties.

Given the results stated above, condition (4.11) can be re-written as:

$$
\frac{(1+\gamma)}{\gamma} \geq \frac{\psi}{3 \phi}
$$


If this condition is met, the four-party system is an equilibrium under majoritarian elections. But this condition is always the case, since as noted in Footnote 16 the right-hand side of (4.12) is smaller than 1, while the left-hand side is above 1 . Hence, under majoritarian elections too, a four party equilibrium always exists.

But now, it is not the only equilibrium. A two-party system is also an equilibrium if all groups prefer to merge rather than to remain split, given that the two opposition groups have also merged, namely if :

$$
\frac{1}{2}{ }_{I I} W^{12} \geq{ }_{I I I} W^{1} .
$$

The right-hand side of (4.13) is the expected payoff to group 1 of remaining a group-specific party while the opposing groups have merged. The left-hand side of (4.13) is the expected payoff accruing to group 1 if it merges with group 2 : the term ${ }_{I I} W^{12}$ is divided in half because each group gets half the party payoff resulting from the merger.

Given the results stated above, condition (4.13) for a two-party equilibrium can be re-written as:

$$
\frac{1+\gamma}{\gamma} \leq \frac{2 \psi}{3 \phi}
$$

Note that the left-hand sides of (4.14) and (4.12) are the same, but the right-hand side of (4.14) is twice as large as the right-hand side of (4.12). Hence, for some parameter values both a two-party and a four-party equilibrium exist (since the left hand side of (4.14) cannot exceed 2, this requires that $\gamma \geq 1$ ).

A two-party equilibrium is more likely to exist if $\psi / \phi=\operatorname{Std}(\omega) / \operatorname{Std}(\delta)$ is large. That is, if aggregate voter mobility is large relative to within-group voter mobility. As the reader may recall, the same conditions make it more likely that equilibrium rents are higher under proportional elections. This makes intuitive sense. If, say, aggregate voter mobility is large $(\operatorname{Std}(\delta)$ small), the election outcome is very uncertain. Then, the electoral advantage of a large party facing two small parties is very significant, cf. (4.4) and (4.3), which naturally raises the incentive to merge. At the same time, rent extraction is punished much more strongly by the voters under majoritarian elections: recall that voter utilities are multiplied by $\psi$ rather than $\phi$ in the expression for expected seat shares. Similarly, small within-group voter mobility $(\operatorname{Std}(\omega)$ large) raises the electoral advantage of a large party.

We summarize the results of this section as follows:

\section{Proposition 4}


Under majoritarian elections, a four-party system is always an equilibrium. But for some parameter values, a two-party system is also an equilibrium outcome. The two-party equilibrium is more likely to exist under the conditions enumerated in Proposition 3, that also make rents higher under proportional than majoritarian elections.

Before turning to the case of heterogeneity, let us try and summarize the empirical implications of the four numbered propositions above. According to Propositions 2 and 4, the equilibrium number of parties and hence the incidence of coalition governments can be smaller under majoritarian elections, particularly under the conditions listed in Proposition 3 (ii). According to Proposition 3 (i), overall government spending is always larger under coalition governments than under single-party governments, and the electoral rule affects spending only via its effect on the incidence of coalition governments. When it comes to rent extraction, the electoral rule has an independent effect, but the sign is ambiguous. By Propositions 3 and 4, however, the smallest rents are likely to be observed in those majoritarian democracies where two-party systems and single-party governments are most often observed.

At a general level, these predictions rhyme well with the general idea in the political-science literature, that proportional elections go hand in hand with "representativeness" and majoritarian elections go hand in hand with "accountability". But the predictions are sharper than general insights, and give quite clear guidance on how we may want to take the model's implications for party structures, types of government, and economic policies to the data.

\section{Heterogeneity}

Heterogeneity in the distribution of voters across districts can be represented in many ways. This section presents a simple model, which illustrates that equilibria under majoritarian elections can be quite different when electoral districts are heterogenous.

As before, we assume that groups $J=3,4$ are homogeneously distributed across districts and, each, constitute one fourth of the electorate. But group $J=1$ now has $\frac{1+\beta}{4}$ of the votes in half of the districts, $d \in\left[0, \frac{1}{2}\right]$ and $\frac{1-\beta}{4}$ of the votes in the other half while the distribution for group $J=2$ is the mirror image of this. Parameter $\beta \in[0,1]$ represents the degree of geographical concentration of groups $J=1$ and 2 . When $\beta=0$, we have the prior homogeneity case, and when $\beta=1$, we have maximum heterogeneity: groups $J=1$ and 2 each represent 
one half of the electorate in one half of the districts, but are not represented at all in the other half. This parametrization has the advantage of preserving symmetry between $J=1$ and 2 while creating asymmetry between the first two and the last two groups.

Intuitively, one would expect parties 1 and 2 to have a "home advantage " in their districts and therefore to have less incentives to merge, while 3 and 4 would have a strong incentive to merge to compete successfully with parties 1 and 2 in their districts. This raises the possibility of a three party equilibrium.

To keep this section short, we present the main results in the form of propositions and intuition for these results. The Appendix gives the details of the underlying calculations. Since proportional elections have only a single national district, heterogeneity cannot be an issue. Hence, we only discuss majoritarian elections.

Proposition 5 compares the equilibrium policy under heterogeneity with the benchmark of the previous section, where all districts are homogeneous. We focus on the policy choices of governments formed by parties $J=1,2$ when in government, i.e., the parties with geographically concentrated representation.

\section{Proposition 5}

When geographical party concentration, as measured by $\beta$, increases:

(i) Coalition governments formed by parties representing geographically concentrated groups spend more on their own groups and even more so when the opposition is split, but spend less on the groups in the opposition, and even more so when the opposition is split;

(ii) Single-party governments formed by a party representing geographically concentrated groups spend the same amount as single-party governments under homogeneous districts, irrespective of the number of parties in the opposition;

(iii) Equilibrium rents are the same as under homogeneity for single-party government, but higher for coalition governments.

The most important result is the first one. Each coalition member has a relatively stronger incentive to please voters from their own constituency in the districts where these voters are overrepresented. The total effect on spending is not clear a priori, however, because higher spending for the groups in government may be more or less than offset by reduced spending for the groups in the opposition. Under heterogeneity, equilibrium policy can vary with the number of parties, in contrast to Proposition 1 and 3. Indeed, when the opposition $(J=3,4)$ is divided, each opposition party receives only half of the votes of the dissatisfied voters, which gives less incentives for the coalition parties to target those groups. 
But the incentive turns the other way if the opposition is united. Note that this result is directly related to the first past the post character of the electoral rule and should be robust to other representations of heterogeneity.

Result (ii) is more directly related to the specific modeling assumptions. When parties 1 and 2 merge, we are back to the homogeneity case with the groups represented in the coalition representing half of the electorate in each district. This result should not be robust to different representations of heterogeneity.

Result (iii) says that total rents are higher under heterogeneity cum coalition governments. This is because, contrary to the case of homogeneity, parties in government mainly compete with the opposition rather than with each other about electoral seats.

The results on equilibrium party formation are expressed in:.

\section{Proposition 6}

Under the above assumptions on heterogeneity:

(i) A two-party equilibrium exists only if $\frac{1+\gamma}{\gamma} \frac{\operatorname{Std}(\delta)}{\operatorname{Std}(\omega)} \leq \frac{2-\beta}{6+\beta}+\frac{1}{3}$;

(ii) A three-party equilibrium with $P=1,2$ remaining split and $P=3,4$ merging always exists if $\frac{2 \beta}{(4+\beta)}-\frac{2-\beta}{2(6+\beta)} \geq \frac{1}{6}$.

The appendix gives the analysis. When $\beta$ increases, the condition for a 2 -party equilibrium becomes more stringent. The main and intuitive insight is that the two parties, $P=1,2$, with a "home advantage" in concentrated districts have less incentives to merge than under homogeneity, because the electoral benefits from doing so are smaller. The main benefit from merging is that reward votes to the coalition partner not well represented in a district are not "lost " but accrue to the merged party. This is not a huge advantage. On the other hand, the cost of sharing power in a merged party remains the same. Therefore, one is less likely to see a two party equilibrium and might see instead a three party equilibrium, as stated in part (ii) of Proposition 6. Note also that the conditions for a three-party equilibrium become more easy to fulfill as heterogeneity goes up ( $\beta$ increases).

The result in Proposition 6 leads to the empirical prediction that two party equilibria and single-party governments are less likely to be observed under majoritarian rule if electoral districts are sufficiently heterogeneous in the distribution of voters. As a corollary, coalition governments should be more frequent, which in turn could lead to a larger government spending. Of course, this prediction may be difficult to take to the data since district heterogeneity is very hard to measure for a large sample of countries. Note that, by Proposition 5, if districts are heterogeneous the electoral rule might exert a direct effect on the overall size 
of government spending, under coalition government. This direct effect of the electoral rule is of ambiguous sign, however, because by Proposition $\mathbf{5}$ higher spending targeted towards groups represented in government may be more than offset by lower spending on opposition groups.

\section{Empirical evidence}

In this section, some of the model's predictions on the causal chain from electoral rules, via political outcomes, to economic policy outcomes, are taken to the data. We use both cross-sectional and panel data for about 50 democracies in the postwar period. The only economic policy variable is overall government spending.

\subsection{The Data}

Our samples As the model in the preceding sections deals with decision-making in a parliamentary democracy, we limit the empirical investigation to democracies with this form of government. Here, we follow Persson and Tabellini (2003), who use the existence of a confidence vote for the executive as the main basis for classifying different forms of government.

We use data from two different data sets, each of which combines information from a variety of second-hand sources and first-hand constitutional documents. For many of the variables, we rely on a broad cross sectional data set assembled and presented in detail in Persson and Tabellini (2003). For some measures of political institutions and outcomes, we use another data set resulting from a collaborative data collection effort jointly with political scientists from Åbo Akademi (see Lundell and Karvonen, 2003).

Our first data set is a cross section of about 50 parliamentary democracies in the 1990s, where each observation is the average of annual data over the period 1990-98. Here, democracies are countries labelled as free or semi-free according to the surveys published by Freedom House. The so-called Gastil indexes of political rights and civil liberties (gastil) vary on a discrete scale from 1 to 7 , with low values associated with better democratic institutions. We include a country in the sample if the average of these two indexes in the 1990-98 period does not exceed 5.

Our second data set covers the period 1960-98 for a smaller group of about 40 parliamentary democracies. Here, we mainly rely on the Polity IV data for the classification into democracies, as this data set goes farther back and is more 
comparable over time than the Freedom House data. Specifically, we use the encompassing polity index, which assigns to each country and year an integer score ranging from -10 to +10 (higher values associated with better democracies), restricting the panel to countries and years with positive values of polity (censored observations are treated as randomly missing). Persson and Tabellini (2003) provide further details on our sample selection criteria. ${ }^{19}$ We use this data set in three ways: First, we average yearly observations throughout the whole period, 1960-98, to draw inference from cross-sectional variation. Second, we use it as a panel, taking the theoretical model literally and defining the relevant time period as a whole legislature (i.e., for all variables we take averages over the yearly outcomes between two consecutive elections). Of course, this does not correspond to the same calendar time for different countries. Third, we use the data set as a standard panel with yearly data.

The variables The model predicts that proportional elections should induce higher government spending. If we ignore the effect on political rents, this is entirely an indirect effect, however, working through a larger number of parties and, thereby, a larger incidence of coalition governments. We should thus find no direct effect of the electoral rule on the size of government, once we account for the different political outcomes caused by different electoral rules. In addition, of course, the model has specific predictions about the signs of various political and economic effects. How do we measure the variables needed to confront these predictions with the data?

Electoral rules In the model, the most important aspect of the electoral system (at least in the sections which abstract from heterogeneity) is the electoral formula: plurality rule versus PR. To capture this, we rely on the binary indicator variable maj, defined and discussed in Persson and Tabellini (2003). The indicator is coded 1 for countries relying exclusively on plurality rule in the elections to the lower house, and 0 otherwise. A few parliamentary democracies rely on a mixed-majoritarian electoral system, with some version of plurality rule in certain districts and proportional rule in others. We code these mixed systems with the dummy variable semi, taking a value of 1 if the electoral system is mixed,

\footnotetext{
${ }^{19}$ For a few small countries, the Polity IV data are not available. We thus interpolate Polity IV with the Freedom House data to make an out of sample prediction. See Persson and Tabellini (2003).
} 
and 0 otherwise. The default is thus the group of proportional countries. Mixedproportional systems such as Germany, for which the electoral formula is strictly proportional at the level of the whole nation, are coded as proportional. ${ }^{20}$ The model also assumes that proportional elections are performed in a nation-wide district and majoritarian elections in single-member districts. In the empirical work, we include the variable district to allow for the positive association expected (from earlier work) between large districts and party proliferation. This variable codes district magnitude in the conventional way, namely as the number of seats awarded in the average electoral district, re-scaled to vary between 0 and 1. These three variables vary both across countries and over time, and they are not very highly correlated with each other (their simple correlation coefficients are always below 0.34 both in the cross sections and in the panel on legislatures). But the time variation is small: there are only seven electoral reforms relevant enough to change our classification of maj or semi, including two reforms in France (that switched from majoritarian and then back to proportional in the mid 1980s) District magnitude varies more frequently over time, although the size of these changes is often small.

Party structure When it comes to the party structure in the legislature, our simplified model has only three possible outcomes: two, three or four parties. To normalize real-world party structures into a comparable measure, we use a Herfindahl-like index of party fragmentation, which is commonly used in the political science literature. It is labeled party_frag and defined as $1-\Sigma_{P}\left(s^{P}\right)^{2}$, where - as in the model $-s^{P}$ is the seat share of party $P$ and the summation runs over all parties in the legislature (lower house). As an alternative measure, we also use the number of parties in the lower house, nparties.

Types of government Our simple model only allows for two types of government: single-party majority and coalition governments; minority governments are not observed. We follow the model, and we classify these types of government through simple indicator variables, called single and coalition, respectively, omitting minority government. Thus, for instance, single takes a value of 1 if the government consists of single-party majority in that year and country, and 0 otherwise. Of course, these two variables do not always sum to 1 for any given country and year, since we sometimes observe minority governments. We never

\footnotetext{
${ }^{20}$ In this respect, our definition of semi differs slightly from the variable mixed in Persson and Tabellini (2003), that instead classified mixed-proportional systems as mixed.
} 
include both single and coalition in the same regression, but we use them as alternatives to assess the robustness of the results. (The two measures correspond to alternative definitions of the default type, minority governments being lumped together with single-party governments when coalition is used, and together with coalition governments when single is used.) When we take the average of these two indicator variables (in the cross sectional estimates or in the course of a legislature), we thus obtain two incidence measures: coalition measures the incidence of coalition governments over the relevant time period, and likewise for single. As an alternative measure of government type, we use the number of parties in the governing coalition, ngov.

Other constitutional variables To identify some of the causal effects described in the theory, we need to measure some other features of the constitution likely to influence either the party structure or the type of government. In particular, in some electoral systems a party has to overcome a minimum electoral threshold to gain representation in the legislature. We call this variable threshold, and measure it as a percent of the total vote at the national level. A higher threshold is expected to reduce party-fragmentation. We also construct $(0,1)$ indicator variables for three additional constitutional features: investiture, set to 1 if a new government must win majority support in an investiture vote; constructive, set to 1 if the government can be dismissed only by electing a replacement; bicam, set to 1 if the legislature has two chambers (irrespective of their relative strength). Bicameralism raises the probability of surplus coalitions (since it increases the majority required to form a government or to pass legislation), and thus we expect it to have a positive effect on the incidence of coalition governments, a negative effect on that of single-party majority governments. The investiture vote and the constructive vote of no confidence reduce the probability of minority governments, and thus, for a given party structure, are expected to increase the incidence of coalition governments, but have no expected effect on single-party majority governments - see, in particular, the recent work by Diermeier, Eraslan, and Merlo (2003a and b). ${ }^{21}$

Both political outcomes and government spending may be influenced by the quality of democracy. We measure it by the Polity IV variable discussed above, interpolated with the Freedom House data set when missing. The resulting variable is called polity_gt.

\footnotetext{
${ }^{21}$ The variable constructive should be treated with care, however, since only two countries in our sample have this constitutional feature.
} 
Finally, when time periods are defined as the whole legislature in our panel data, we also measure the length of the legislature, leg_length, in years, to control for different durations of legislatures.

Economic and social variables To measure the overall size of government, we rely on central government spending as a percent of GDP, cgexp, defined and discussed in Persson and Tabellini (2003). This measure is based on data from the IMF. Since government spending is affected by many other determinants, we also control for several variables that reflect the economical, political, geographical, and historical characteristics of the countries in the sample. These variables are discussed and defined more extensively in Persson and Tabellini (2003). Some of them are only used in the cross-sectional estimates, some only in the panel estimates, some in both.

The following variables refer to economic and social determinants of fiscal policy or of political outcomes: openness to international trade, measured as exports plus imports over GDP (trade), population size measured in logs (lpop), the percentage of the population above 65 years of age (prop65), the log of real per capita income (lyp), the output gap (ygap), measured as the log-deviation of output from the country specific trend, a measure of ethno-linguistic fractionalization (avelf). These variables have been shown to correlate with measures of fiscal policy in previous studies, such as Cameron (1978), Rodrik (1998), and Persson and Tabellini (2003).

To measure the influence of colonial history, and since many majoritarian countries are also former British colonies, we typically control for British colonial origin. Because the influence of colonial heritage is likely to fade with time, we weigh colonial origin by the time since independence, giving more weight to colonial history in young independent states and no weight at all to colonial rule more than 250 years ago. The colonial history variable is called col_uka.

Finally, since spending refers to central government, we also use an indicator variable for federal political structures (federal).

The results reported below are very robust to alternative specifications of these control variables. To save on degrees of freedom, we generally include these controls only when they are statistically significant, or when we have strong priors that they really belong to the specification.

Preliminary inspection of the data Table 1 displays means and standard deviations of the main variables of interest, in the three types of electoral sys- 
tems, majoritarian, mixed and proportional. Each observation corresponds to a particular legislature in a particular country in the 1960-98 panel. The statistics in the table are computed from pooling together these observations. Most observations are either classified as majoritarian or proportional. Comparing these two more extreme electoral systems, we immediately find large differences in line with all the predictions of the theory. Majoritarian electoral systems have a less fragmented party system, a smaller incidence of coalition governments, a larger incidence of single party government, and smaller government spending, compared to proportional systems. The few mixed electoral systems display outcomes in between the polar types. Interestingly, $63 \%$ of the observations from majoritarian countries exhibit single-party government, whereas the incidence for proportional countries is only $17 \%$. Taking our model literary, the residual presence of coalition governments under majoritarian elections might reflect either the multiplicity of equilibria or heterogeneity of districts in a subset of countries. Note also that the standard deviation of the type of government is large within each class of electoral rules, suggesting that there may also be independent shocks to coalition formation, a feature not present in our model (see further below).

As discussed above, however, the theory has additional and precise predictions that go beyond such simple cross tabulations. Moreover, in Table 1 we are not controlling for other differences across countries or time periods. In the remainder of this section we show that more sophisticated statistical analysis confirms the simple message of Table 1 and provides support for the precise predictions of the theory.

\subsection{Cross sectional estimates}

We first confront the predictions of the theory with the cross country-variation in the data. We use both our cross sections: the one for the 1990s includes a larger number of countries for a single decade; and the one for 1960-98 includes a smaller number of countries for (at most) four decades.

First, we study the predictions of the theory concerning the political variables, asking how party structure and type of government vary with electoral rules. Second, we study the economic predictions, asking how the electoral rules influence government spending. Since we have relatively few observations, we keep the specification with regard to other variables as parsimonious as possible. 
Political effects of electoral rules Table 2 reports our estimates of the political effects, part $a$ for the 1990s cross section, part $b$ for the 1960-98 cross section. Since the layout of both tables is the same, we comment on them together.

First, we ask how the electoral rule shapes the party structure, as measured by party fragmentation (party_frag) and by the number of parties (nparties). We use a slightly more parsimonious specification in the longer cross section in Table 2b, where we have fewer observations, but we always control for UK colonial origin and for country size. Ethno-linguistic fragmentation is only available in the 1990s, so we control for it in Table 2a. Columns 1 and 2 of both tables display the results. As expected, plurality rule (as measured by $\mathrm{maj}_{\text {) }}$ is associated with less party fragmentation and fewer parties. Mixed electoral systems also seem to lead to less fragmented party systems (compared to the proportional default), although the effect is marginally significant only in the larger sample from the 1990s. Also as expected, larger electoral districts (typical of proportional elections) are associated with a more fragmented party system and a larger number of parties. Finally, electoral thresholds influence the party structure as expected (higher thresholds, fewer parties), but the effect is only significant for the number of parties.

Next, we estimate a reduced form for the type of government. Here, besides the features of the electoral rule and the other regressors, we also control for the constitutional features mentioned above: bicameralism, investiture vote, and constructive vote of no confidence. ${ }^{22}$ The results are displayed in columns 3-5 of Tables $2 a$ and $b$, with coalition governments, single-party majority governments, and number of parties in government, as the dependent variable. Only some of the electoral rule variables are statistically significant, and the results vary according to the sample and the type of government indicators. This might be due to some correlation between some of these indicators (in particular between district magnitude and the indicators for the electoral formula). Nevertheless, the overall effects go in the expected direction. Larger electoral districts raise the incidence of coalition governments and the number of parties in government, and tend to reduce the incidence of single party-majority government (the last effect is only significant in the $1960-98$ cross section). Plurality rule raises the incidence of single-party majorities. Among the other constitutional variables,

\footnotetext{
${ }^{22}$ We do not include investiture and constructive in the regression where single is the dependent variable, because these two variables are expected to reduce the incidence of minority government, and thus should have no effect on single-party majority, given the party system see the dicussion above. We also omit bicameralism from the longer cross sections for 1960-98, because it is not available over such a long period.
} 
bicameralism and the constructive vote of no confidence raise the incidence of coalition governments, as expected, while the investiture vote is not statistically significant.

Finally, the theory predicts that the electoral system influences the type of government only through its effect on the party structure. To test this prediction, we estimate the type of government regressions by two-stage least squares, using the electoral rules variables as instruments for party fragmentation (or the number of parties in government). Because we have an additional variable (threshold) measuring the electoral rule, beyond maj, semi and district, and given that the electoral rule variables are not highly mutually correlated (and measure different features of electoral rules) we can test the over-identifying restriction that they are valid instruments, i.e., that electoral rules do not exert an independent influence in the second-stage regression for the type of government.

The results are displayed in columns 6-8 of Tables 2a and 2b. Party fragmentation has a strong and significant effect on the type of government, with the expected sign, and the number of parties in the legislature have a significant effect on the number of parties in government. The estimated coefficients of the party structure variables on the type of government are precisely estimated, and their size is similar across the two samples, a sign of robustness. Moreover, we cannot reject the over-identifying restrictions that the electoral-rule variables have no direct effect on the type of government once we allow for the effect of party structure, except in the case of coalition governments in Table $2 a$, where we marginally reject at the $5 \%$ confidence level - cf. the row labelled Over-id.

This last set of results also give some comfort against the risk of misspecification. As mentioned in connection with Table 1, the observed variation in the type of goverment within electoral rules suggests stochastic shocks to government formation. Such shocks might be systematically correlated with electoral rules, through strategic decisions in government and/or party formation. Ideally, these issues should be analyzed in the context of our model, but unfortunately the mechanical government formation stage does not permit such analysis. Neverthelss, our general inability to reject the over-identifying restrictions reassures us that neglecting these issues does not bias our inference.

Overall, these estimates are remarkably consistent with the predictions of the theory.

Economic effects of electoral rules We now turn to the second set of predictions, concerning the effects on the size of government spending, cgexp. 
Throughout, we control for the economic, social, historical and geographic variables listed in Section 6.1, such as federalism, demographics, and British colonial origin; the specification is a bit more parsimonious in the 1960-98 sample, because we have fewer degrees of freedom and because some controls are not available over this longer time period (see the notes to Table 3 for details). The results are very robust to alternative specifications of the set of controls.

The reduced-form estimates are displayed in columns 1 and 2 of Table 3, for the 1990 and the 1960-98 samples respectively. To save on degrees of freedom, we omit the variable for mixed electoral system (semi) for the 1960-98 sample; we also omit the constitutional variables, bicam, investiture and constructive. District magnitude (district) has a very strong positive effect on the size of government, as expected. Plurality rule $(m a j)$ also has the expected (negative) effect, but the estimated coefficient is not statistically significant. We omit the electoral threshold variable, as it is never statistically significant.

The remaining columns of Table 3 ask whether the effect of the electoral rule on government spending operates through the type of government, and only through that channel. As before, we measure the type of government alternatively as the incidence of coalition governments (coalition), the incidence of single party majority government (single), and the number of parties in government (ngov). The instruments for the type of government are the electoral-rule variables as displayed in columns 1 and 2 of Table 3 respectively, plus the investiture vote variable when the type of government is measured by coalition, and the electoral threshold variable when it is measured by the number of parties in government. ${ }^{23}$ The estimated effects of the type of government on government spending are strongly significant with the predicted sign. The coefficients are not very precisely estimated, but the point estimates are often large enough to keep them comfortably away from zero (at $95 \%$ confidence). Finally, we cannot reject the over-identifying restrictions, that the electoral-rule variables have no direct influence on government spending, beyond their indirect influence through the type of government.

In summary, then, the cross-sectional estimates support all the predictions of the theory. Altogether, they suggest that proportional electoral rules indeed cause larger government spending than majoritarian electoral rules in the way our model predicts: they lead to more fragmented party systems and hence to more frequent coalition governments.

\footnotetext{
${ }^{23}$ Given the caveats above, we prefer not to use the constructive vote variable as an instrument, although its inclusion makes no difference. Here we also skip the intervening step of the party structure, regressing the type of government directly on the electoral rule variables.
} 


\subsection{Panel estimates}

In this subsection we turn to the time variation in the data. On the one hand, this exercise is more demanding, as electoral rules only exhibit limited variation over time. There have been a few reforms of electoral formulas, generally towards a mixed system from both extremes (plurality and strict proportionality), mainly but not exclusively in the 1990s. Variations in the magnitude of electoral districts have been somewhat more common. But variations in the type of government occur more frequently.

On the other hand, using the time variation in the data is also more rewarding. Inference about true causality drawn from time-series variation may be more reliable than inference from cross-country variation, because simultaneity bias due to omitted (time-invariant) confounding variables is less likely.

We confine the analysis to the 1960-98 data set. As discussed above, we define a time period as either a whole legislature, or a calendar year. Defining time periods to conform with legislatures allows us to remain more faithful to the theoretical model. This is the unit of time over which our political and institutional variables remain constant (in practice, for party structure or type of government, or by definition, for the electoral rules variables). Time measured in legislatures seems particularly appropriate when studying the political effects of electoral rules. Because almost all the reforms are clustered in the two most recent decades, we include at most six legislatures in each country in the legislatures panel. When it comes to government spending, however, it may also be relevant to consider calendar time, because different countries may be affected by worldwide events in similar ways, and because the duration of legislatures varies across countries. For government spending we thus show results also for a yearly panel.

Our empirical strategy is similar to the one in the previous section. We start by the political effects of electoral rules, then go on to study their effects on government spending. In both cases, we estimate reduced forms, as well as structural forms. Panel data analysis raises a few new estimation issues. All our endogenous variables (party structure, type of government, spending) move slowly over time. The endogenous variables are also likely to reflect the effect of unobserved, country-specific determinants. To cope with these features of the data, we report on estimates obtained by two alternative methods.

One method is to estimate in levels, including country fixed effects and lagged dependent variables (but no correction for serial correlation). This is equivalent to estimating the parameters of interest from variables measured as deviations from country means. It is well known that fixed-effects estimates are biased in 
the presence of lagged dependent variables. But the bias becomes negligible if the panel is sufficiently long. In our yearly panel, we have on average 25 years per country so the problem is likely to be negligible.

With only six observations per country in the legislature panel, however, the bias can be more serious. In these cases, we instead estimate in first differences by GMM, with the procedure pioneered by Arellano and Bond (1991). Here, we use lags of dependent and endogenous variables, and exogenous variables as instruments. This method produces consistent estimates even if the error term has first-order serial correlation, and makes efficient use of the instruments. But it makes some demanding assumptions on the validity of the instruments. Because of the uncertain finite-sample properties of GMM estimators with many overidentifying restrictions, we choose a parsimonious set of instruments, exploiting only one extra lag of dependent or endogenous variables (rather than the full set of lags to the beginning of the sample).

We comment more extensively on these methods in context. Generally, and luckily, they produce similar estimates.

Political effects of electoral rules Table 4 displays the political effects of alternative electoral rules as estimated from the legislatures panel. The structure of the table is similar to that of Table 2. Thus, we first ask how electoral rules influence party fragmentation (here we omit the number of parties); then, how they (and other electoral /constitutional variables) influence the type of government on reduced form; finally, how party structure influences the type of government, including the test of whether electoral rules affect the type of government exclusively through party structure.

Columns 1 shows GMM estimates (for first differences) of the effect of electoral rules on party fragmentation. We include lagged party fragmentation, and control for country size (measured by population) and quality of democracy (measured by polity_gt), as many countries in the sample have become better democracies in more recent periods. As expected, district magnitude raises party fragmentation, confirming the cross sectional results in Table 2. Plurality rule (measured by $\mathrm{maj}$ ) has the expected negative sign, but is at best borderline significant ( $p$-value of 0.11). We cannot reject the assumptions of no second-order serial correlation or validity of the lagged values used as instruments.

The reduced form results for coalition and single-party governments are displayed in columns 2-3. We now include two lags of the dependent variable in the specification, plus the quality of democracy and population size. The constitu- 
tional variables used in the corresponding cross-sectional estimates (bicameralism, investiture vote and constructive vote of no confidence), can no longer be included since they exhibit too little time variation. ${ }^{24}$ The results again remind of the results in Table 2. Larger district magnitude significantly raises the likelihood of coalition governments, while plurality rule raises the likelihood of single-party governments. The coefficients are not very precisely estimated. Evidently, there is considerable time variation in the type of government, which cannot be easily explained on the basis of the sluggish electoral rule variables.

Columns 4 and 5 report on the structural estimates for the type of government. In the specification, we thus treat party fragmentation as endogenous, and use the electoral-rule variables (in first differences) as additional instruments (beyond one additional lag of the dependent variable and one lag of endogenous party fragmentation). The estimated coefficients on party fragmentation are significant with the expected sign: more fragmentation increases the likelihood of coalition governments and reduces the likelihood of single-party majorities. Moreover, we cannot reject the over-identifying assumptions on the validity of the instruments, meaning that the electoral rule variables do not exert a direct effect on the type of government.

While these panel estimates are not as precise as the cross-sectional estimates, they still confirm our earlier inference and give further support to the predictions of the model.

Economic effects of electoral rules Last, we return to the effects of the electoral rule on government spending with a similar specifications as in the cross sectional regressions. Table 5 reports on estimates based on the legislature panel as well as the yearly panel. The dependent variable is always overall government spending. But in the legislature panel, we always measure the size of government spending in the last year of the legislature (rather than on average throughout the legislature), to allow the political variables to exercise their full effect. In the GMM estimates where the data are differenced, the dependent variable is thus defined as the change in spending from the end of the previous legislature to the end of the current one. Since the duration of legislatures varies across countries and time periods, these regressions include a variable measuring the length of the legislature, in years. Lagged spending is also included in the specification: one (differenced) lag in the GMM estimates on the legislature panel, and two (level) lags in the fixed-effect estimates on the yearly panel.

\footnotetext{
${ }^{24}$ Constructive actually varies over time, but only for Belgium in 1993.
} 
The specifications always include other time-varying determinants of government spending, such as the output gap (to measure cyclical influences on government spending), openness to international trade, and the proportion of the elderly in the population. Finally, to reduce collinearity among the electoral rule variables, we omit the indicator variable for mixed electoral rules, including only the indicator for plurality rule ( $m a j)$ and the measure of district magnitude (district).

Columns 1 and 2 of Table 5 show the reduced form of spending on the electoral rule variables. As expected, district magnitude has a positive and strongly significant coefficient (larger districts implying more spending). But the coefficient on plurality rule is insignificant.

The remainder of the table displays the structural estimates. Columns 3 and 4 show the GMM estimates of the type of government (coalition or single party majority) on government spending for the legislature panel, where the type of government is endogenous and the electoral rule variables of column 1 are used as additional instruments. Columns 5 and 6 show the fixed-effect, instrumentalvariable estimates; here the lagged type of government and the electoral-rules variables are used to instrument for the current type of government.

The estimated coefficients all have the expected sign: coalition governments spend more, single party majority governments spend less. The effect of coalition governments is precisely estimated and large in value. Given the coefficients on lagged spending, the implied long-run effect is $10 \%$ of GDP in column 3, and $6 \%$ of GDP in column 5, thus of the same magnitude as the cross sectional estimates. The effect of single-party government is smaller and much less precisely estimated. However, note that the over-identifying restrictions now can be rejected for the fixed effect estimates (time periods measured in years), while they cannot for the GMM estimates.

All in all, the panel estimates are a bit more fragile than the cross-sectional estimates, but that is perhaps to be expected given the paucity of real-worldreforms in our data. On the whole, they give additional support to the main insights from the theory: proportional electoral rules are associated with more fragmented party systems, more coalition governments, and these spend more than single-party majority governments.

\section{Concluding remarks}

This paper investigates the effects of electoral rules in parliamentary democracies. In line with the recent paper by Bawn and Rosenbluth (2002), we study a formal 
model that incorporates two key ideas. The first idea is that plurality rule gives an electoral advantage to larger parties, since they are more likely to gain plurality in each district. For this reason, strategic politicians have a strong incentives to merge into a large party under plurality rule, whereas they prefer to splinter in many smaller parties under proportional elections. This strategic behavior of politicians has obvious implications for the type of government. Under plurality rule, we are more likely to see governments supported by single party majorities, whereas coalition governments are more likely under proportional rule.

The second idea is that single-party governments and coalition governments differ in a crucial respect. When the government is supported by a single-party majority, voters cannot easily discriminate between different politicians in government. Therefore, the main electoral conflict runs between government and opposition. A coalition government allows voters to discriminate at the polls between the coalition parties, and this creates electoral conflicts within the government coalition. As we have seen, that intra-government conflict induces higher spending under both electoral rules.

To model these two ideas in a simple way, we have had to rely on simplifying assumptions, restricting the feasible alliances among politicians and simplifying the voters' behavior. But we think that the main insights of the paper are robust to alternative modelling assumptions. Our simplifications enable us to study a complete politico-economic equilibrium, which yields precise predictions on the whole chain of causal effects, from electoral rule, to party structure, to type of government, to economic policy. Moreover, we obtain additional insights. According to the theory, if electoral districts are homogeneous, the electoral rule influences economic policy and type of government exclusively through its effect on party structure. If the electoral districts are heterogeneous, party fragmentation and coalition governments are likely to arise also under plurality rule.

Empirical evidence, based on the observed variation across parliamentary democracies and across time in connection with electoral reforms, strongly supports the main theoretical predictions. Proportional rule is indeed associated with more fragmented party structures, which in turn lead to more frequent coalition governments, which spend more than single-party majority governments. Moreover, the electoral rule does not seem to exert direct influence on the type of government, nor on the size of government spending. The chain of causation in the data appears to coincide with the causal chain predicted by the theory.

The theoretical model also has other predictions, that we have not yet exploited in the empirical analysis. In particular, political rents are predicted to be higher 
under coalition governments. And heterogeneity of political districts should influence government spending, as well as political outcomes, but only under plurality rule. Moreover, we have confined the theoretical and empirical analysis to the overall size of government spending. But the crucial difference between coalition and single-party governments emphasized in this paper is likely to influence other economic policy dimensions, such as the size of budget deficits or the composition of spending and taxation. We leave these promising and exciting topics for future research. 


\section{Appendix: Heterogeneity and majoritarian elections}

In districts $d \in\left[0, \frac{1}{2}\right], J=1$ constitutes a share $\frac{1+\beta}{4}$ of the electorate while $J=2$ constitutes only a share $\frac{1-\beta}{4}$ of voters while in districts $d \in\left(\frac{1}{2}, 1\right]$, it is the opposite. Groups $J=3$, 4 each form a quarter of the electorate in each district.

\subsection{Equilibrium policy choices}

As in sections 3 and 4, we derive first the equilibrium policy under coalition and single-party government and then analyze equilibrium party formation.

\subsubsection{Coalition government.}

We first look at the case where parties $P=3,4$ remain split.

Split opposition (4 parties) In districts $d \in\left[0, \frac{1}{2}\right]$, the competition will be between $P=1$ and $P=3$ or 4 . The latter are expected to have an equal number of votes so let us focus on the competition between $P=1$ and $P=3$. The vote share for $P=1$ is given by

$$
\begin{aligned}
v^{1}= & \frac{1+\beta}{4} F\left(V^{1}-V^{1 *}-\delta\right)+ \\
& \frac{1}{8} \sum_{J=3}^{4} F\left(V^{J}-V^{J *}-\delta\right)
\end{aligned}
$$

Similarly, the vote share of $P=3$ is given by

$$
\begin{aligned}
v^{3}= & \frac{1+\beta}{8}\left(1-F\left(V^{1}-V^{1 *}-\delta\right)\right)+ \\
& \frac{1-\beta}{8}\left(1-F\left(V^{2}-V^{2 *}-\delta\right)\right) \\
& \frac{1}{4}\left(1-F\left(V^{3}-V^{3 *}-\delta\right)\right)
\end{aligned}
$$

Note that $P=3$ gets only half of the votes of the disgruntled voters from $J=1$ since $P=4$ gets the other half. We can then calculate

$$
\begin{aligned}
\operatorname{Pr} o b\left(v^{1} \geq\right. & \left.v^{3}\right)=\frac{1}{2}+\frac{\psi \beta}{2 \phi(4+\beta)}+\frac{\psi}{4+\beta}\left[(1+\beta) \frac{3}{2}\left(V^{1}-V^{1 *}\right)\right. \\
& \left.+\frac{1-\beta}{2}\left(V^{2}-V^{2 *}\right)+\frac{3}{2}\left(V^{3}-V^{3 *}\right)+\frac{1}{2}\left(V^{4}-V^{4 *}\right)\right]
\end{aligned}
$$


Therefore, the expected seat share of $P=1$ is half that amount since it has no chance of winning in the second half of the districts:

$$
\begin{aligned}
E\left(I V s_{C}^{1}\right)= & \frac{1}{4}+\frac{\psi \beta}{4 \phi(4+\beta)}+\frac{\psi}{2(4+\beta)}\left[(1+\beta) \frac{3}{2}\left(V^{1}-V^{1 *}\right)+\right. \\
& \left.\frac{1-\beta}{2}\left(V^{2}-V^{2 *}\right)+\frac{3}{2}\left(V^{3}-V^{3 *}\right)+\frac{1}{2}\left(V^{4}-V^{4 *}\right)\right]
\end{aligned}
$$

$E\left({ }_{I V} s_{C}^{2}\right)$ is defined analogously.

Assuming a similar competition between $P=2$ and 4, one easily derives the equilibrium policies under a four party equilibrium:

$$
\begin{aligned}
& { }_{I V} g_{C}^{J}=\left\{\begin{array}{lll}
H_{g}^{-1}\left[\frac{4+\beta}{6(1+\beta)}\right] & \text { if } & J=1,2 \\
H_{g}^{-1}\left[1+\frac{\beta}{4}\right], & \text { if } & J=3,4
\end{array}\right. \\
& { }_{I V} r_{C}^{1}={ }_{I V} r_{C}^{2}=\frac{4}{\gamma \psi}
\end{aligned}
$$

As one sees, spending on voters represented in the coalition increases with $\beta$ but spending on voters from the opposition decreases with $\beta$.

Merged opposition (three parties) We now look at the equilibrium policies when the opposition merges and the coalition faces opposition party $P=34$. We proceed as above.

In districts $d \in\left[0, \frac{1}{2}\right]$, the vote share for $P=1$ remains the same and is given by (8.1). On the other hand, the votes for $P=34$ are given by

$$
\begin{aligned}
v^{34}= & +\frac{1+\beta}{4}\left(1-F\left(V^{1}-V^{1 *}-\delta\right)\right)+ \\
& \frac{1-\beta}{4}\left(1-F\left(V^{2}-V^{2 *}-\delta\right)\right) \\
& \left.\frac{1}{4} \sum_{J=3}^{4}\left(1-F\left(V^{J}-V^{J *}-\delta\right)\right)\right\}
\end{aligned}
$$

This is exactly the double of $v^{3}$ as given by (8.1). We can then derive the expected seat share of $P=1$.

$$
\begin{aligned}
E\left({ }_{I I I} s_{C}^{1}\right)= & \frac{1}{4}-\frac{\psi\left(1-\frac{\beta}{2}\right)}{2(6+\beta) \phi}+\frac{\psi}{4(6+\beta)}\left[(1+\beta) 4\left(V^{1}-V^{1 *}\right)\right. \\
& \left.+(1-\beta) 2\left(V^{2}-V^{2 *}\right)+3 \sum_{J=3}^{4}\left(V^{J}-V^{J *}\right)\right]
\end{aligned}
$$


Clearly the equilibrium expected seat shares for $P=1,2$ will be lower when the opposition is united. Equilibrium policies will however also be different:

$$
\begin{aligned}
& { }_{I I I} g_{C}^{J}=\left\{\begin{array}{lll}
H_{g}^{-1}\left[\frac{6+\beta}{8(1+\beta)}\right] & \text { if } & J=1,2 \\
H_{g}^{-1}\left[1+\frac{\beta}{6}\right], & \text { if } & J=3,4
\end{array}\right. \\
& { }_{I I I} r_{C}^{1}={ }_{I I I} r_{C}^{2}=\frac{4}{\gamma \psi}
\end{aligned}
$$

One sees that compared to $(8.2), J=3,4$ receive more public goods and $J=1,2$ receive less even though there is still overspending for the former and underspending for the latter. The reason is that a united opposition is a more serious contender because it receives more votes than a single party in a divided opposition. On the other hand, reward and punishment votes from voters not represented in government are split between the coalition parties. This gives an incentive to the incumbents to please more the groups from the opposition and to spend less on its constituencies.

One sees here that in a coalition government, the equilibrium policy does change with the number of parties in the opposition. This is thus different from what we have under homogeneity where equilibrium policy depends only on the government structure and not on the number of parties.

As above, an increase in $\beta$ leads to an increase in spending on voters from the coalition parties and to an decrease in spending on voters from the opposition.

\subsubsection{Single party government}

We now analyze the case where $J=1$ and 2 merge to form a single party $P=12$.

Analyzing first the case with a split opposition, the vote share of that party in the first half of the districts will be

$$
\begin{aligned}
v^{12}= & \frac{1+\beta}{4} F\left(V^{1}-V^{1 *}-\delta\right)+ \\
& \frac{1-\beta}{4} F\left(V^{2}-V^{2 *}-\delta\right)+ \\
& \frac{1}{4} \sum_{J=3}^{4} F\left(V^{J}-V^{J *}-\delta\right)
\end{aligned}
$$


In the other half of districts, the expression will be similar with $V^{2}$ replacing $V^{1}$.

On the other hand, the vote share for $P=3$ is given by (8.1).

The expected seat share of $P=12$ is then

$$
E\left(s^{12}\right)=\frac{1}{2}+\frac{\psi}{6 \phi}+\frac{\psi}{4}\left(\sum_{J=1}^{4}\left(V^{J}-V^{J *}\right)\right.
$$

Note that the expression between square brackets has the same "weights " for the groups represented in government and for those in the opposition. The equilibrium policy is thus the same as in proportional and majoritarian homogeneous elections! Heterogeneity thus does not affect the equilibrium policy when there is a single-party government. The reason is that the single party is represented equally in all districts. We are back to a case with symmetry. We do not expect this result to hold under alternative representations of heterogeneity.

One verifies easily that the case with merged opposition will deliver similar results. In essence, it becomes a 2-party contest like the one analyzed in the homogeneous case.

\subsection{Equilibrium party formation}

Let us now look at possible equilibria. We first inspect the conditions for a two party equilibrium.

Let us first look at the incentives for $P=12$ to merge or to split given that $P=34$ has merged. In a two party equilibrium, the expected seat share of $P=12$ will be $\frac{1}{2}$ whether it is in the opposition or not. The expected payoff of a merger for party 1 is then $\frac{1}{2}{ }_{I I} W_{G}^{12}=\frac{1+\gamma}{\gamma \psi}$. In a three party equilibrium where $P=1$ and 2 remain split, party $P=1$ or 2 gets $_{I I I} W_{G}^{P}=\frac{1}{2}\left[1+E\left({ }_{I I I} s_{C}^{P}\right) \gamma 2\right] \frac{4}{\gamma \psi}+\frac{1}{2} E\left({ }_{I I I} s_{O}^{P}\right) \frac{4}{\gamma \psi} \gamma 2$. From (8.3) we know that $E\left({ }_{I I I} s_{C}^{P}\right)=\frac{1}{4}-\frac{\psi\left(1-\frac{\beta}{2}\right)}{2(6+\beta) \phi}$. Assuming that $P=34$ are in power, one can then derive that $E\left({ }_{I I I} s_{O}^{P}\right)=\frac{1}{4}-\frac{\psi}{12 \phi}$. One can then derive the condition for $P=12$ to merge:

$$
\frac{1+\gamma}{\gamma} \frac{\phi}{\psi}=\frac{1+\gamma}{\gamma} \frac{\operatorname{Std}(\delta)}{\operatorname{Std}(\omega)}<\frac{2-\beta}{6+\beta}+\frac{1}{3}
$$

The right hand side unambiguously declines with $\beta$ making the condition more difficult to fulfill as $\beta$ increases. 
To prove the existence of a two party equilibrium, not only must (A10) be verified, but $P=3$ and 4 must prefer to be merged rather than to stay split given that $P=1,2$ are merged. When merged, the payoff to $P=3$ or 4 will be $\frac{(1+\gamma)}{\gamma \psi}$ and when split, it will be $\frac{2(1+\gamma)}{\gamma \psi}-\frac{2}{3 \phi}$. The condition to merge given that 1 and 2 have merged is thus

$$
\frac{1+\gamma}{\gamma} \frac{\phi}{\psi}<\frac{2}{3}
$$

Note that inequality (A10) is more stringent than (A11).

For a three party equilibrium with $P=3,4$ merging to exist, one must verify whether $P=3$ and 4 prefer to merge when 1 and 2 prefer to remain split. Reversed inequality (A10) gives the condition for 1 and 2 to remain split when $P=3,4$ have merged.

Under a three party equilibrium, $\frac{1}{2}{ }_{I I I} W_{G}^{34}=\frac{1}{4}\left[1+E\left({ }_{I I I} s_{S}^{34}\right) \gamma\right] \frac{4}{\gamma \psi}+\frac{1}{4} E\left({ }_{I I I} s_{O}^{34}\right) \frac{4}{\gamma \psi} \gamma$. We derive:

$$
\frac{1}{2}_{I I I} W_{G}^{34}=\frac{(1+\gamma)}{\gamma \psi}+\frac{1}{6 \phi}+\frac{2-\beta}{2 \phi(6+\beta)}
$$

With four parties, the payoff to party $P=3,4$ is ${ }_{I V} W_{G}^{P}=\frac{1}{2}\left[1+E\left({ }_{I V} s_{C}^{P}\right) \gamma 2\right] \frac{4}{\gamma \psi}+$ $\frac{1}{2} E\left({ }_{I V} s_{O}^{P}\right) \frac{8}{\gamma \psi} \gamma$. We get

$$
{ }_{I V} W_{G}^{P}=\frac{2(1+\gamma)}{\gamma \psi}-\frac{2 \beta}{\phi(4+\beta)}
$$

Therefore, ${ }_{I V} W_{G}^{P}<\frac{1}{2}{ }_{I I I} W_{G}^{34}$ if and only if

$$
\frac{1+\gamma}{\gamma} \frac{\phi}{\psi}<\frac{2 \beta}{(4+\beta)}+\frac{2-\beta}{2(6+\beta)}+\frac{1}{6}
$$

Note that the right hand side increases with $\beta$.

For a three party equilibrium, given (A10), we must thus have

$$
\frac{2-\beta}{6+\beta}+\frac{1}{3}<\frac{2 \beta}{(4+\beta)}+\frac{2-\beta}{2(6+\beta)}+\frac{1}{6}
$$

i.e. $\frac{2 \beta}{(4+\beta)}-\frac{2-\beta}{2(6+\beta)}>\frac{1}{6}$. This inequality will not hold for $\beta=0$ but will hold for $\beta=1$. One also sees that the left-hand side monotonically increases with $\beta$. There is thus a threshold $\beta^{*} \in(0,1)$ above which a three party equilibrium will exist. Heterogeneity can thus lead to a three party equilibrium. 


\section{References}

[1] Arellano, S. and M. Bond 1991. "Some Tests of Specification for Panel Data: Monte Carlo Evidence and an Application to Employment Equations." Review of Economic Studies 58, 277-297.

[2] Austen-Smith, D. 2000. "Redistributing Income under Proportional Representation." Journal of Political Economy 108, 1235-1269.

[3] Baron, D. and D. Diermeier. 2001. "Elections, Governments, and Parliaments in Proportional Representation Systems." Quarterly Journal of Economics, 116, 933-967.

[4] Bawn, K. and F. Rosenbluth. 2002. "Coalition Parties versus Coalitions of Parties. How Electoral Agency Shapes the Political Logic of Costs and Benefits ", working paper, Yale.

[5] Besley T. and S. Coate. 2003. "Elected versus Appointed Regulators: Theory and Evidence", Journal of the European Economic Association, forthcoming.

[6] Cameron, D. 1978. "The Expansion of the Public Economy: A Comparative Analysis." American Political Science Review 72, 1203-1261.

[7] Cox, G. 1990. "Centripetal and Centrifugal Forces in Electoral Systems" American Journal of Political Science 34, 903-935.

[8] Cox, G. 1997. Making Votes Count. Cambridge, UK: Cambridge University Press.

[9] Diermeier, D., and T. Feddersen 1998. "Cohesion in Legislatures and the Vote of Confidence Procedure." American Political Science Review 92, 611-621.

[10] Diermeier, D.and A. Merlo, 2000. "Government Turnover in Parliamentary Democracies ", Journal of Economic Theory 94, 46-79.

[11] Diermeier, D., H. Eraslan, and A. Merlo. 2003a. "A Structural Model of Governmment Formation." Econometrica 71, 27-70.

[12] Diermeier, D., H. Eraslan, and A. Merlo. 2003b. "Bicameralism and Governmment Formation." working paper, University of Pennsylvania. 
[13] Laver, M. and N. Schofield. 1990. Multiparty Government: The Politics of Coalition in Europe, paperback edition Oxford.

[14] Laver, M. and K. Shepsle. 1996. Making and Breaking Governments - Cabinets and Legislatures in Parliamentary Democracies. New York: Cambridge University Press.

[15] Lijphart, A. 1984a. Democracies. New Haven: Yale University Press.

[16] Lijphart, A. 1984b. "Advances in the Comparative Study of Electoral Systems." World Politics 36, 424-436.

[17] Lijphart, A. 1994. Electoral Systems and Party Systems. Oxford: Oxford University Press.

[18] Lijphart, A. 1999. Patterns of Democracy: Government Forms and Performance in Thirty-Six Countries. New Haven, CT: Yale University Press.

[19] Lundell, K. and L. Karvonen. 2003. A Comparative Data Set on Political Institutions, mimeo, Åbo Akademi.

[20] Milesi-Ferretti G-M., Perotti, R. and M. Rostagno 2002. "Electoral Systems and the Composition of Public Spending." Quarterly Journal of Economics 117, 609-657.

[21] Persson, T., G. Roland and G. Tabellini 2000. "Comparative Politics and Public Finance." Journal of Political Economy 108, 1121-1161.

[22] Persson, T. and G. Tabellini 1999. "The Size and Scope of Government: Comparative Politics with Rational Politicians, 1998 Alfred Marshall Lecture." European Economic Review 43, 699-735.

[23] Persson, T. and G. Tabellini 2000. Political Economics: Explaining Economic Policy. Cambridge, MA: MIT Press.

[24] Persson, T. and G. Tabellini 2003. The Economic Effects of Constitutions. Cambridge, MA: MIT Press.

[25] Persson, T. and G. Tabellini 2004. "Constitutional Rules and Economic Policy Outcomes" American Economic Review, forthcoming 
[26] Persson, T., G. Tabellini, and F. Trebbi 2003. "Electoral Rules and Corruption" Journal of the European European Economic Association 1, 958-989.

[27] Powell Jr., G. Bingham 1982. Contemporary Democracies: Participation, Stability and Violence. Cambridge, UK: Cambridge University Press.

[28] Powell Jr., G. Bingham 2000. Elections as Instruments of Democracy. New Haven and London: Yale University Press.

[29] Rodrik, D. 1998. "Why Do More Open Economies Have Bigger Governments?" Journal of Political Economy 106, 997-1032.

[30] Taagepera, R. and M. Shugart 1989. Seats and Votes: The Effects and Determinants of Electoral Systems. New Haven: Yale University Press. 
Table 1

Political and economic outcomes

in alternative electoral systems

\begin{tabular}{lccc}
\hline & Majoritarian & Mixed & Proportional \\
\hline party fragmentation & 0.54 & 0.54 & 0.70 \\
& $(0.17)$ & $(0.12)$ & $(0.09)$ \\
coalition governments & 0.24 & 0.33 & 0.55 \\
& $(0.41)$ & $(0.47)$ & $(0.47)$ \\
single-party governments & 0.63 & 0.40 & 0.17 \\
& $(0.47)$ & $(0.50)$ & $(0.37)$ \\
government spending & 25.94 & 33.45 & 35.12 \\
& $(9.05)$ & $(11.3)$ & $(9.30)$ \\
\hline N. obs. & 138 & 7 & 187 \\
\hline
\end{tabular}

Simple averages; standard deviations in parenthesis.

Observations pooled across countries and legislatures. 
Table 2a

Party Structure, type of governments and electoral rules

OLS and instrumental variable estimates in 1990s cross section

\begin{tabular}{|c|c|c|c|c|c|c|c|c|}
\hline & $(1)$ & (2) & (3) & (4) & (5) & (6) & $(7)$ & $(8)$ \\
\hline Dep. Var. & party_frag & nparties & coalition & single & ngov & coalition & single & ngov \\
\hline party_frag & & & & & & $\begin{array}{l}2.01 \\
(0.71)^{\star * *}\end{array}$ & $\begin{array}{l}-2.78 \\
(0.50)^{* * *}\end{array}$ & \\
\hline nparties & & & & & & & & $\begin{array}{l}0.25 \\
(0.10)^{* *}\end{array}$ \\
\hline maj & $\begin{array}{l}-0.12 \\
(0.05)^{* *}\end{array}$ & $\begin{array}{l}-2.10 \\
(1.31)\end{array}$ & $\begin{array}{l}-0.16 \\
(0.23)\end{array}$ & $\begin{array}{l}0.42 \\
(0.17)^{* *}\end{array}$ & $\begin{array}{l}0.08 \\
(0.85)\end{array}$ & & & \\
\hline semi & $\begin{array}{l}-0.22 \\
(0.09)^{\star *}\end{array}$ & $\begin{array}{l}-3.76 \\
(2.23)^{*}\end{array}$ & $\begin{array}{l}0.32 \\
(0.22)\end{array}$ & $\begin{array}{l}-0.28 \\
(0.10)^{* * *}\end{array}$ & $\begin{array}{l}0.98 \\
(1.03)\end{array}$ & & & \\
\hline district & $\begin{array}{l}0.11 \\
(0.07)\end{array}$ & $\begin{array}{l}3.20 \\
(1.56)^{* *}\end{array}$ & $\begin{array}{l}0.66 \\
(0.26)^{* *}\end{array}$ & $\begin{array}{l}-0.30 \\
(0.19)\end{array}$ & $\begin{array}{l}2.22 \\
(1.15)^{*}\end{array}$ & & & \\
\hline threshold & $\begin{array}{l}0.00 \\
(0.01)\end{array}$ & $\begin{array}{l}-0.39 \\
(0.16)^{* *}\end{array}$ & $\begin{array}{l}0.03 \\
(0.03)\end{array}$ & $\begin{array}{l}-0.01 \\
(0.02)\end{array}$ & $\begin{array}{l}-0.09 \\
(0.12)\end{array}$ & & & \\
\hline bicam & & & $\begin{array}{l}0.23 \\
(0.10)^{* *}\end{array}$ & $\begin{array}{l}-0.11 \\
(0.09)\end{array}$ & $\begin{array}{l}0.06 \\
(0.33)\end{array}$ & $\begin{array}{l}0.15 \\
(0.11)\end{array}$ & $\begin{array}{l}-0.01 \\
(0.08)\end{array}$ & $\begin{array}{l}0.28 \\
(0.24)\end{array}$ \\
\hline investiture & & & $\begin{array}{l}-0.16 \\
(0.21)\end{array}$ & & $\begin{array}{l}0.95 \\
(0.84)\end{array}$ & $\begin{array}{l}-0.08 \\
(0.12)\end{array}$ & & $\begin{array}{l}0.84 \\
(0.35)^{\text {** }}\end{array}$ \\
\hline constructive & & & $\begin{array}{l}0.47 \\
(0.14)^{\star * *}\end{array}$ & & $\begin{array}{l}-0.04 \\
(0.77)\end{array}$ & $\begin{array}{l}0.53 \\
(0.10)^{* * *}\end{array}$ & & $\begin{array}{l}0.19 \\
(0.33)\end{array}$ \\
\hline Over-id & & & & & & $7.91(3)^{\star *}$ & $4.33(3)$ & $4.52(3)$ \\
\hline Estimation & OLS & OLS & OLS & OLS & OLS & 2SLS & 2SLS & 2SLS \\
\hline Adj.R-sq. & 0.47 & 0.44 & 0.39 & 0.51 & 0.22 & & & \\
\hline N. Obs. & 52 & 52 & 47 & 47 & 47 & 47 & 47 & 47 \\
\hline
\end{tabular}

Robust standard errors in parentheses; * significant at $10 \%$; ** significant at $5 \%$; ** significant at $1 \%$

Controls included in all OLS specifications, cols (1)-(5): avelf, lpop, col_uka

Second-stage variables in 2SLS regressions, cols (6)-(8): avelf, lpop, col_uka, bicam, investiture, constructive

First-stage variables in the 2SLS specifications: maj, semi, district, threshold, and all second-stage variables

Over-id is Hansen's J test statistic of the over-identifying restriction implied by the electoral rule variables having no direct effect on the type government; critical values at $5 \%$ significance 7.81 , cols (6)-( 8 ) 
Table $2 b$

Party Structure, type of governments and electoral rules

OLS and instrumental variable estimates in 1960-98 cross section

\begin{tabular}{|c|c|c|c|c|c|c|c|c|}
\hline & $(1)$ & $(2)$ & (3) & $(4)$ & (5) & $(6)$ & (7) & $(8)$ \\
\hline Dep.Var & party_frag & nparties & coalition & single & ngov & coalition & single & ngov \\
\hline party_frag & & & & & & $\begin{array}{l}2.62 \\
(0.74)^{* * *}\end{array}$ & $\begin{array}{l}-2.63 \\
(0.43)^{* * *}\end{array}$ & \\
\hline nparties & & & & & & & & $\begin{array}{l}0.24 \\
(0.06)^{* * *}\end{array}$ \\
\hline$m a j$ & $\begin{array}{l}-0.09 \\
(0.05)^{*}\end{array}$ & $\begin{array}{l}-1.88 \\
(1.48)\end{array}$ & $\begin{array}{l}0.07 \\
(0.20)\end{array}$ & $\begin{array}{l}0.20 \\
(0.18)\end{array}$ & $\begin{array}{l}0.44 \\
(0.83)\end{array}$ & & & \\
\hline semi & $\begin{array}{l}-0.01 \\
(0.06)\end{array}$ & $\begin{array}{l}-1.29 \\
(1.81)\end{array}$ & $\begin{array}{l}0.25 \\
(0.19)\end{array}$ & $\begin{array}{l}0.02 \\
(0.20)\end{array}$ & $\begin{array}{l}0.39 \\
(0.74)\end{array}$ & & & \\
\hline district & $\begin{array}{l}0.14 \\
(0.07)^{\star *}\end{array}$ & $\begin{array}{l}5.02 \\
(1.79)^{* * *}\end{array}$ & $\begin{array}{l}0.75 \\
(0.20)^{* * *}\end{array}$ & $\begin{array}{l}-0.43 \\
(0.23)^{*}\end{array}$ & $\begin{array}{l}2.22 \\
(0.74)^{* * *}\end{array}$ & & & \\
\hline threshold & $\begin{array}{l}-0.01 \\
(0.01)\end{array}$ & $\begin{array}{l}-0.77 \\
(0.27)^{\star * *}\end{array}$ & $\begin{array}{l}-0.01 \\
(0.04)\end{array}$ & $\begin{array}{l}-0.00 \\
(0.03)\end{array}$ & $\begin{array}{l}-0.16 \\
(0.13)\end{array}$ & & & \\
\hline investiture & & & $\begin{array}{l}0.04 \\
(0.19)\end{array}$ & & $\begin{array}{l}0.84 \\
(0.81)\end{array}$ & $\begin{array}{l}-0.10 \\
(0.11)\end{array}$ & & $\begin{array}{l}0.35 \\
(0.34)\end{array}$ \\
\hline constructive & & & $\begin{array}{l}0.71 \\
(0.20)^{\star * *}\end{array}$ & & $\begin{array}{l}0.42 \\
(0.51)\end{array}$ & $\begin{array}{l}0.78 \\
(0.12)^{\star * *}\end{array}$ & & $\begin{array}{l}0.77 \\
(0.48)\end{array}$ \\
\hline Over-id & & & & & & $4.25(3)$ & $2.76(3)$ & $3.65(3)$ \\
\hline Estimation & OLS & OLS & OLS & OLS & OLS & 2SLS & 2SLS & 2SLS \\
\hline Adjust. R-sq. & 0.40 & 0.49 & 0.25 & 0.34 & 0.11 & & & \\
\hline N. obs & 38 & 38 & 36 & 36 & 36 & 36 & 36 & 36 \\
\hline
\end{tabular}

Robust standard errors in parentheses; * significant at $10 \% ;{ }^{* *}$ significant at $5 \%$; ${ }^{* *}$ significant at $1 \%$

Controls included in all OLS specification, cols (1)-(5): lpop, col_uka

Second-stage variables in 2SLS regressions, cols (6)-(8): lpop, col_uka, investiture, constructive

First-stage variables in the 2SLS specifications: maj, semi, district, threshold, and all second-stage variables

Over-id is Hansen's J statistic for test of the over-identifying restriction implied by the electoral rule variables having no direct effect on the type of government;

critical values at $5 \%$ significance are 7.81 in all columns 
Table 3

Size of government in the cross sections

OLS and instrumental variable estimates

\begin{tabular}{|c|c|c|c|c|c|c|c|c|}
\hline & (1) & (2) & (3) & (4) & (5) & (6) & (7) & $(8)$ \\
\hline Dep. Var. & cgexp & cgexp & cgexp & cgexp & cgexp & cgexp & cgexp & cgexp \\
\hline maj & $\begin{array}{l}-4.76 \\
(3.39)\end{array}$ & $\begin{array}{l}-2.73 \\
(2.55)\end{array}$ & & & & & & \\
\hline semi & $\begin{array}{l}8.31 \\
(4.53)^{*}\end{array}$ & & & & & & & \\
\hline district & $\begin{array}{l}14.52 \\
(2.05)^{* * *}\end{array}$ & $\begin{array}{l}17.29 \\
(2.29)^{* * *}\end{array}$ & & & & & & \\
\hline coalition & & & $\begin{array}{l}17.00 \\
(3.72)^{* * *}\end{array}$ & & & $\begin{array}{l}30.07 \\
(10.79)^{* * *}\end{array}$ & & \\
\hline single & & & & $\begin{array}{l}-17.17 \\
(5.58)^{* * *}\end{array}$ & & & $\begin{array}{l}-24.47 \\
(14.97)\end{array}$ & \\
\hline ngov & & & & & $\begin{array}{l}7.74 \\
(4.06)^{*}\end{array}$ & & & $\begin{array}{l}10.01 \\
(5.47)^{*}\end{array}$ \\
\hline Over-id & & & $2.16(3)$ & $2.26(2)$ & $0.02(2)$ & $1.29(2)$ & $1.60(1)$ & $1.70(2)$ \\
\hline Sample & $1990 \mathrm{~s}$ & $1960-98$ & $1990 \mathrm{~s}$ & $1990 \mathrm{~s}$ & $1990 \mathrm{~s}$ & $1960-98$ & $1960-98$ & $1960-98$ \\
\hline Estimation & OLS & OLS & 2SLS & 2SLS & 2SLS & 2SLS & 2SLS & 2SLS \\
\hline Obs. & 46 & 34 & 46 & 46 & 46 & 34 & 34 & 34 \\
\hline Adj. R-sq & 0.67 & 0.55 & & & & & & \\
\hline
\end{tabular}

Robust standard errors in parentheses; $\quad$ * significant at $10 \%$; ** significant at $5 \%$; *** significant at $1 \%$

Variables included in OLS specification, col (1), and second stage of 2SLS specification, cols (3)-(5): lyp, trade, prop65, federal, avelf, col_uka Variables included in OLS specification, col (2), and second stage of 2SLS specification, cols (6)-(8): lyp, prop65, federal, col_uka

First-stage in 2SLS specifications: as displayed in cols 1-2 plus investiture (in cols 3 and 6) and threshold (in cols 5 and 8), plus all second-stage variables Over-id is Hansen's J test statistic for test of the over-identifying restriction implied by the electoral rule and constitutional variables having no direct effect on the size of government; critical values at $5 \%$ significance are 7.81(col 3), 5.99(cols 4, 5, 6 and 8), 3.84 (col 7) 
Table 4

Political outcomes in panel - periods correspond to legislatures

GMM estimates

\begin{tabular}{|c|c|c|c|c|c|}
\hline & $(1)$ & $(2)$ & (3) & $(4)$ & (5) \\
\hline Dep. Var. & party_frag & coalition & single & coalition & single \\
\hline \multirow{2}{*}{ party_frag } & & & & 1.35 & -1.26 \\
\hline & & & & $(0.81)^{*}$ & $(0.63)^{* *}$ \\
\hline \multirow{2}{*}{ maj } & -0.06 & 0.37 & 0.14 & & \\
\hline & $(0.04)$ & $(0.48)$ & $(0.09)^{*}$ & & \\
\hline \multirow[t]{2}{*}{ district } & 2.31 & 6.31 & -0.10 & & \\
\hline & $(0.24)^{\star * *}$ & $(3.02)^{* *}$ & $(0.56)$ & & \\
\hline \multirow[t]{2}{*}{ threshold } & -0.00 & 0.16 & -0.00 & & \\
\hline & $(0.00)$ & $(0.10)$ & $(0.01)$ & & \\
\hline Over-id & $4.16(3)$ & $0.01(1)$ & $2.48(1)$ & $3.83(6)$ & $3.70(6)$ \\
\hline $\mathrm{AR}(2)$ & 0.68 & -0.02 & 0.93 & 0.01 & 0.46 \\
\hline Estimation & GMM & GMM & GMM & GMM & GMM \\
\hline Obs. & 141 & 97 & 97 & 97 & 97 \\
\hline N. countries & 37 & 35 & 35 & 35 & 35 \\
\hline
\end{tabular}

Robust standard errors in parentheses; * significant at $10 \%$; ** significant at $5 \%$; ${ }^{* *}$ significant at $1 \%$.

Estimation method: Arellano-Bond GMM estimates (all variables in first differences).

Specification: always included, constant, lpop; polity_gt, and lagged Dep. var., once in col (1), twice in cols (2) - (5)).

In cols (1)-(5), instruments for lagged Dep. Var. is one additional lag of this variable.

In cols (4)-(5), party_frag is treated as endogenous with additional instruments: one lag of party_frag, maj, district, .and threshold..

AR(2) Arellano-Bond test for absence of second-order serial correlation.

Over-id: Sargan test of over-identifying restrictions, distributed as Chi2 with degrees of freedoms in parenthesis;

critical values at $5 \%$ confidence: $7.81 \mathrm{col}(1), 3.84$ cols (2)-(3), 12.59 cols (4)-(5). 
Table 5

Size of government in panel

GMM and FE estimates

\begin{tabular}{|c|c|c|c|c|c|c|}
\hline & $(1)$ & (2) & (3) & $(4)$ & (5) & (6) \\
\hline Dep var & last_cgexp & cgexp & last_cgexp & last_cgexp & cgexp & cgexp \\
\hline$m a j$ & $\begin{array}{l}1.08 \\
(1.67)\end{array}$ & $\begin{array}{l}-0.86 \\
(0.60)\end{array}$ & & & & \\
\hline district & $\begin{array}{l}0.25 \\
(0.08)^{* * *}\end{array}$ & $\begin{array}{l}0.42 \\
(0.15)^{\star * *}\end{array}$ & & & & \\
\hline threshold & $\begin{array}{l}-0.12 \\
(0.17)\end{array}$ & $\begin{array}{l}-0.18 \\
(0.19)\end{array}$ & & & & \\
\hline coalition & & & $\begin{array}{l}6.51 \\
(3.12)^{* *}\end{array}$ & & $\begin{array}{l}0.94 \\
(0.38)^{* *}\end{array}$ & \\
\hline single & & & & $\begin{array}{l}-1.79 \\
(4.31)\end{array}$ & & $\begin{array}{l}-0.52 \\
(0.33)\end{array}$ \\
\hline$L(1)$ dep var & $\begin{array}{l}0.53 \\
(0.21)^{* *}\end{array}$ & $\begin{array}{l}0.93 \\
(0.03)^{\star * *}\end{array}$ & $\begin{array}{l}0.46 \\
(0.18)^{* *}\end{array}$ & $\begin{array}{l}0.66 \\
(0.17)^{\star * *}\end{array}$ & $\begin{array}{l}0.98 \\
(0.04)^{\star * *}\end{array}$ & $\begin{array}{l}0.98 \\
(0.04)^{\star * *}\end{array}$ \\
\hline$L(2)$ dep var & & $\begin{array}{l}-0.08 \\
(0.03)^{* *}\end{array}$ & & & $\begin{array}{l}-0.14 \\
(0.04)^{* * *}\end{array}$ & $\begin{array}{l}-0.13 \\
(0.04)^{* * *}\end{array}$ \\
\hline Periods & legislatures & years & legislatures & legislatures & years & years \\
\hline Over-id & $5.35(3)$ & & $10.24(9)$ & $7.11(9)$ & $8.66(3)^{\star *}$ & $9.49(3)^{* *}$ \\
\hline $\mathrm{AR}(2)$ & 0.76 & & 0.52 & 0.96 & & \\
\hline Estimation & GMM & $\mathrm{FE}$ & GMM & GMM & FEIV & FEIV \\
\hline Obs. & 111 & 889 & 105 & 105 & 822 & 822 \\
\hline $\mathrm{N}$ countries & 34 & 36 & 32 & 32 & 34 & 34 \\
\hline
\end{tabular}

Standard errors in parentheses, robust in cols (1),(3)--(4) * significant at 10\%; ** significant at $5 \%$; ${ }^{* * *}$ significant at $1 \%$.

Estimation methods: FE: with country fixed effects. FEIV: fixed-effects instrumental-variable estimates.

GMM Arellano-Bond estimates (all variables in first differences).

Specification : always included: constant, lpop, prop65, ygap; in cols (1), (3)-(4) leg_length.

In col (1), instruments for lagged last_cgexp is one further lag of this variable.

In cols (3)-(4), type of government (coalition or single) is treated as endogenous with one lag of this variable plus maj, district, and threshold as instruments.

In cols (5)-(6), instruments for type of government is lagged type of government, plus maj, district, and threshold.

$\mathrm{AR}(2)$ Arellano-Bond test for absence of second order serial correlation.

Over-id: Test of over-identifying restrictions, distributed like Chi2 with degrees of freedoms in parenthesis;

critical values at 5\% confidence: 7.81 cols (1), (5)-(6); 16.92 cols (3)-(4). 